\title{
Southern African Wave Model Sensitivities and Accuracies
}

\author{
Christo Rautenbach ${ }^{1,2,3,4, * \mathbb{D}}$, Michael A. Barnes ${ }^{5}\left(\mathbb{D}\right.$, David W. Wang ${ }^{6}$ and James Dykes ${ }^{6}(\mathbb{D}$ \\ 1 Research and development, MetOcean (a division of the Meteorological Service), Raglan 3225, New Zealand \\ Environmental Research Institute, University of Waikato, Hamilton 3240, New Zealand \\ 3 Institute for Coastal and Marine Research, Nelson Mandela University, Port Elizabeth 6031, South Africa \\ 4 Department of Oceanography and Marine Research Institute, University of Cape Town, Rondebosch 7701, \\ South Africa \\ 5 Marine Research Unit, South African Weather Service, Cape Town 7525, South Africa; \\ michael.barnes@weathersa.co.za \\ 6 Oceanography Division, Naval Research Laboratory, Stennis Space Center, MS 39529, USA; \\ David.Wang@nrlssc.navy.mil (D.W.W.); jimddykes@gmail.com (J.D.) \\ * Correspondence: rautenbachchristo@gmail.com
}

Received: 30 August 2020; Accepted: 26 September 2020; Published: 1 October 2020

\begin{abstract}
Numerous studies have identified the complexities of the wave climatology around the South African coast, but limited studies have investigated these complex dynamics in the available literature. Several freely available parameterized wave boundary conditions are produced around southern Africa. However, none of these are fully spectral outputs from global or larger regional spectral wave models. This constraint results in local engineering and scientific organizations, reconstructing their own spectral boundary conditions. For coastal models, this is a reasonable assumption, assuming that the single parameterization is accurate and a representation of a non-multimodal sea state. The South African Weather Service (SAWS) Marine unit recently launched their coupled, operational wave and storm surge forecasting model. The aim of the SAWS Wave and Storm Surge (SWaSS) platform was to provide accurate, high-resolution coastal forecasts for the entire South African coastline. The present investigation thus presents the validation of the spectral wave component of the coupled system, developed in Delft3D. Various wave boundary reconstructions are investigated together with the two most used and well-known whitecapping formulations. Validation is performed with both in situ wave-rider buoy data (at nine locations along the coastline) and regional remotely sensed, along track, altimetry data. Full model performance statistics are provided, and the accuracy of the model is discussed.
\end{abstract}

Keywords: waves; spectral wave modelling; extreme events; operational forecasting; numerical modelling; WAVEWATCH III; SWAN; South Africa; boundary conditions; whitecapping

\section{Introduction}

Southern Africa has been known for its extreme wave climate for centuries. In the 1600s, the Cape Peninsula was dubbed the "Cape of Good Hope", but also the "Cape of Storms", due to the large number of merchant ships that sank in extreme storm conditions [1]. Since then, South Africa has developed into a cosmopolitan African nation with over nine major ports. The coastline stretches over $3000 \mathrm{~km}$ from the Namibian boarder on the west to the Mozambique boarder on the east. The climatology of South Africa also varies significantly around the coastline [2]. The wave climate follows suit, with different atmospheric drivers dictating the timing and intensity of wave events around the coastline [3-5]. 
The characteristics of the atmospheric and oceanographic systems affecting the wave climate in a particular area is important for accurate wave model setups. Both the spectral wave model settings and physics and the assumptions made with regard to forcing and boundary conditions are important for accurate wave predictions [6]. According to [7], the southern Indian Ocean (in the so-called Roaring Forties wind belt) requires approximately $30 \mathrm{~h}$ to produce a swell signal, which then propagates through the entire Indian Ocean. The same is true for the swell signals generated in the Roaring Forties in the Atlantic Ocean [8]. It takes approximately $84 \mathrm{~h}$ for the swell waves to travel to the tropical water of the southern Indian Ocean while the swell waves will reach South Africa much sooner [9]. Ref. [10] presented austral summer and winter averages of both swell and wind wave significant wave heights. Here, the non-homogeneous pattern of global wave fields is clear, especially on the edges of the Roaring Forties. The dominance of wind waves (the so-called "wind wave zones") in the Southern Ocean is also evident, in this classification called "swell pools" [7,11]. The majority of the oceans surrounding southern Africa is a mixture between swell- and wind-dominant waves, according the same classification [11,12], also presenting patterns of wave generation zones, with southern Africa being distinctly in its own zone. Global distributions of wind sea and swell probabilities, indices and significant wave heights (based on collocated TOPEX/NSCAT and TOPEX/QSCAT datasets) also confirm the heterogeneous behaviour of the southern African wave fields [11]. Simulating, understanding and capturing this heterogeneous behaviour for the global wave fields is also important for future projections of expected wave climate changes [12-14]. According to a recent study, approximately $50 \%$ of the world's coastlines are at risk due to projected global wave climate change [13,15]. On the west and south coast of South Africa, the projected mean wave directional changes are between 1 and 3 degrees (counter-clockwise) by 2100 [13].

The accurate coastal prediction of waves is important for coastal planning, management and governance $[16,17]$. Even small changes in wave direction or total experienced energy could have drastic effects on coastal sediment transport rates (e.g., [18]) and ecosystem stability (e.g., [19]). Waves also play a crucial role in coastal storm surge forecasting, especially in areas frequented by large wave events, like southern Africa [4,5,20].

The South African Weather Service (SAWS) recently developed an operational Wave and Storm Surge (SWaSS) [21] forecasting platform [4]. The model was developed as an online, coupled system between the Simulating Waves in the Nearshore (SWAN) model and a depth-averaged Delft3D hydrodynamic (FLOW) model. As part of the total SWaSS model calibration, the sensitivity of the wave model component is assessed and presented here. Limited research has been done on the regional wave climate behaviour around South Africa. Recently, the importance of wave-current interactions over the Agulhas retroflexion area [22] and the core of the Agulhas Current (close to the South African east coast) [23] have been noted.

The sensitivities of regional- and local-scale (down to approximately 300 to $500 \mathrm{~m}$ resolution) spectral wave models have not yet been investigated for southern Africa. Similar studies have, however, been performed in other regions, such as in the Mediterranean Sea (e.g., [24]), the Indian east coast (e.g., [6]), and the Arabian Sea (e.g., [6]). Global models lack the resolution required for bay-scale accuracy due to local bathymetric features, local friction, and local orography related to wind-wave growth and whitecapping energy dissipation. Therefore, global models are predominantly unable to accurately reproduce local wave measurements $[6,25]$. Local wave forecasting is also not the main aim of global wave models. The aforementioned models do, however, provide boundary conditions to regional models and are archived in numerous, storage space-efficient, ways. These storage techniques can vary in reliability in terms of representing the correct wave energy distribution at a particular point (e.g., the amount of energy associated with wind or swell seas). The parameter and/or partition reconstruction method used in a regional or local model could then lead to wave energy (significant wave height and period), directional and/or event arrival time mismatches at a particular coastline.

In the present study, the prediction sensitivity of a regional SWAN spectral wave model for southern Africa is thus investigated. Three spectral boundary condition reconstructions are implemented 
to investigate their ability to reproduce observed coastal wave records and regional wave fields. The creation of the wave parameters and partitions are discussed, and the assumptions related to the reconstruction of representative spectral boundary conditions are elucidated. These boundary conditions are spatially and temporally varying and are compared through the results of a regional SWAN model forced with fully spectral boundary conditions, as produced by a global WAVEWATCH III ${ }^{\circledR}$ model (WW3). Variations in wind forcing are not tested here (as discussed by [24] for the Mediterranean Sea) and are assumed to be accurate based on a recent study by [4]. The prediction accuracy effects of two well-established whitecapping formulations are, however, investigated and discussed, similar to the recent investigation by [26].

\section{Data}

\subsection{Bathymetry Data}

The bathymetry used in the present study was primarily based on the General Bathymetric Chart of the Oceans (GEBCO) and supplemented with high-resolution bathymetry in the vicinity of South African ports and in situ measurement locations. These data were provided by the South African Navy Hydrographic Office (SANHO). In Figure 1, the southern African model bathymetry is given. From the west to the east, the major coastal locations are Saldanha Bay (SB), Cape Town (CT), Mossel Bay (MB), Port Elizabeth (PE), East London (EL), Durban (DU) and Richard's Bay (RB).

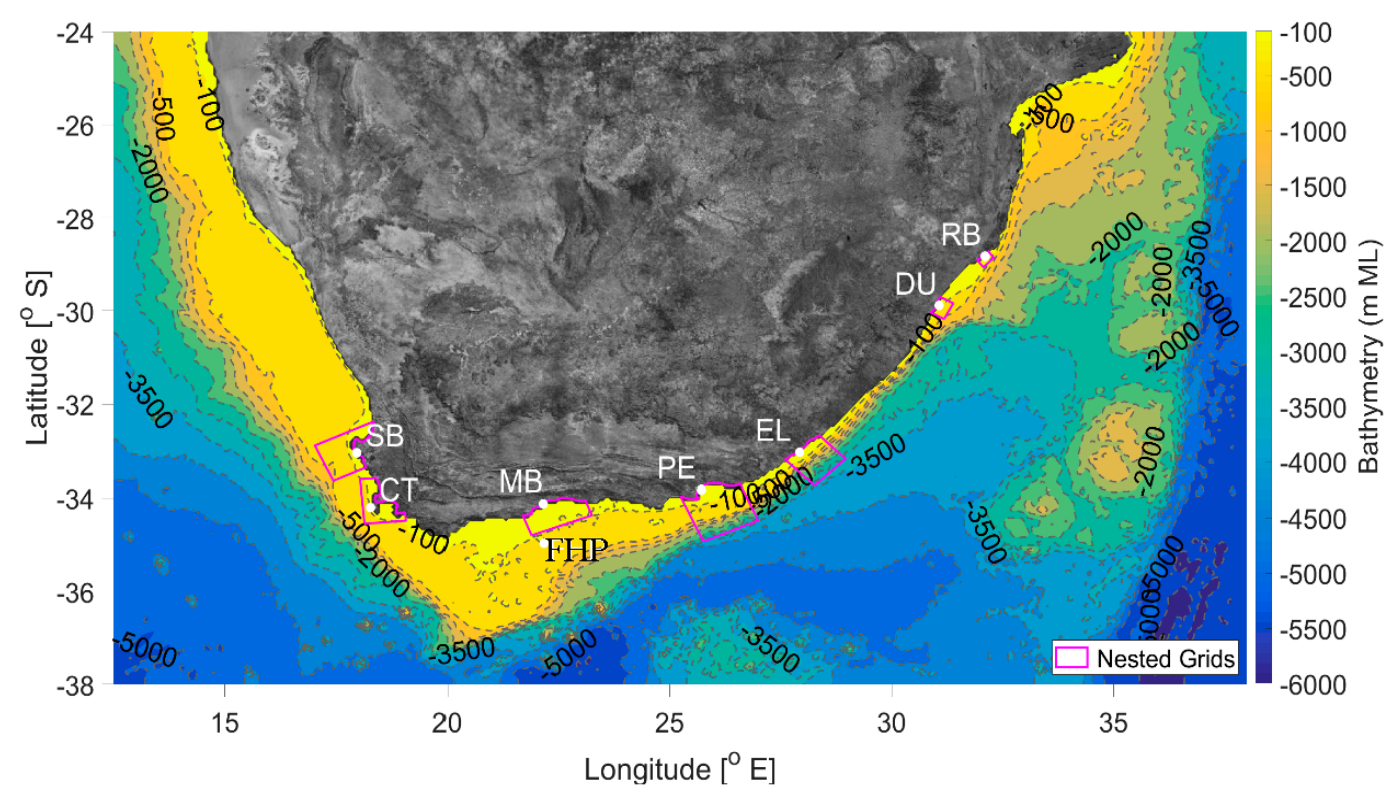

Figure 1. South African bathymetry and regional model extent. Magenta enclosures indicate SWAN nested domains. Major coastal city locations are given via acronyms.

\subsection{Wave Data}

Wave buoy data were provided by Transnet National Port Authorities (TNPA) for all nine coastal in situ measurement locations. These data are archived and maintained by the Council for Scientific and Industrial Research (CSIR) in Stellenbosch, South Africa. The wave rider buoy mooring depths varied between $21 \mathrm{~m}$ and $95 \mathrm{~m}$, chart datum (CD) (here, CD values are determined by the South African hydrographic office and is usually defined as the vertical datum corresponding to the lowest low astronomical tide or land levelling datum). The FH Platform buoy (refer to Figure 1) is the in situ observation location furthest offshore and is situated adjacent to the south coast, close to the edge of the Agulhas Bank (southern South Africa's continental shelf [27]). A summary of the in situ wave rider buoy data used in the present study is presented in Table 1 . 
Table 1. Datawell wave rider buoy mooring depths (CD) and geographical coordinate location. Data quality control was performed at the Council for Scientific and Industrial Research (CSIR) in Stellenbosch, South Africa. The Datawell wave rider buoy used at each location is described as non-directional (ND) or multi-directional (MD), together with the model description. FHP was the only location where a WaMoS II wave radar system was used to gather data.

\begin{tabular}{ccccccccc}
\hline Description & SB & SK $^{*}(\mathbf{C T})$ & MB & PE & EL & FHP & DB & RB \\
\hline Water depth $[\mathrm{m}]$ & 23 & 70 & 24 & 21 & 27 & 95 & 30 & 22 \\
Latitude $\left[{ }^{\mathbf{0}}\right]$ & -33.05 & -34.204 & -34.12467 & -33.83333 & -33.038 & -34.97 & -29.884 & -28.8265 \\
Longitude $\left[{ }^{\mathbf{0}}\right]$ & 17.978 & 18.28667 & 22.1535 & 25.71666 & 27.93083 & 22.17 & 31.07067 & 32.104 \\
Directional & ND & MD & ND & MD & MD & MD & MD & MD \\
Model & SG & MK2 & SG & MK3 & MK3 & WMS II & MK4 & MK 4 \\
\hline
\end{tabular}

* Slangkop (SK) is the local name for the mooring location just outside of Cape Town, offshore of Hout Bay.

\subsection{Altimetry Data}

Global measurements of significant wave heights are provided along tracks of satellite radar altimeters. In the present study, data from the JASON-3 [28] and AltiKa [29] missions were used for the regional SWAN model performance evaluation. These types of satellites are usually placed in near-polar, sun-synchronous orbits. Their nadir-looking instruments, which measure along a narrow beam directly below the satellite, measure scattered energy, which is the basis for the derived wave height and wind speed. The along-track resolution of the altimeter data is approximately $7 \mathrm{~km}$, and their separation, depending on orbit geometry, can be up to $400 \mathrm{~km}$ at the equator. Satellites repeat the same ground tracks on a 3- to 10-day repeat cycle. This provides a reasonable coverage of the ocean surface in large scales but is not suitable for smaller domains in the littoral.

The altimeter data used in the WW3 model data assimilation and model performance evaluations were processed through an application from the Navy Coupled Ocean Data Assimilation (NCODA) [30] software. The global WW3 model (used as the source of the fully spectral boundary conditions in the present study) validation results is known as Ocean Quality Control (OCNQC) and these results are made available on the Global Ocean Data Assimilation Experiment (USGODAE) server (https://usgodae.org) [31].

\subsection{Wind Data}

The South African Weather Service (SAWS) operational Unified Model (UM) output was used as atmospheric forcing for all the SAWS wave and surge models. The model resolution was approximately $4.4 \mathrm{~km}$ [32]. Model wind parameters and atmospheric pressure were assumed to be accurate for the purposes of the present study based on coastal validations presented by [4]. Atmospheric forcing for the Navy global WW3 model, from which boundary conditions were obtained, consisting of $10 \mathrm{~m}$ winds from the U.S. Navy Global Environmental Model (NAVGEM), run at Fleet Numerical Oceanography and Meteorology Centre (FNMOC).

\section{Numerical Models}

Two spectral numerical wave models are implemented in the present study. WW3 is used to simulate global scale wave dynamics and produced boundary conditions for a regional and local scale SWAN domain. The SWAN domains were thus off-line nested in the Wave Watch III global computational grid.

\subsection{WAVEWATCH III ${ }^{\circledR}($ WW3)}

This is a third-generation phase-averaged wave model that solves the spectral action-density balance equation for wave number-direction spectra [33-35]. Developed by [36], the multi-grid approach of WW3 allows the computation of multiple grids using a single model run. With two-way communication between grids, wave spectra cross all domain boundaries in both directions at frequency 
intervals. The resulting advantages include (1) increased accuracy in the vicinity of the boundaries assuming the wind conditions are also consistent, (2) decreased human error in model domain setup, where the interpolation and other logistics are internally handled, and (3) a streamlined model setup, eliminating the additional steps of managing additional nested runs.

The U.S. Navy currently runs global WW3 systems at the Fleet Numerical Meteorology and Oceanography Center (FNMOC) at both Stennis Space Center, Mississippi, and Monterey California. Since the global grids used in these systems typically operated with regular latitude/longitude spacing, it attempts to cover the Arctic region with small time steps at the risked of violating the Courant-Friedrichs-Lewy (CFL) condition. Consequentially, an upgrade to a three-grid system to cover the globe has been validated and has nearly been transitioned to operation. This new system was implemented for the experiments described in the current study.

The United States Naval Research Laboratory (NRL) developed a set of new configurations consisting of an irregular-regular-irregular (IRI) multi-grid system of three grids: one with regular spacing (in terms of latitude and longitude) at low latitudes and two polar stereographic grids at high latitude in the northern and southern hemisphere respectively [37]. The northern polar stereographic grid includes the entire Arctic Ocean (albeit with the North Pole masked to prevent a singularity associated with angle conventions in WW3). Of the collection of configurations with their different resolutions, NRL selected the $1 / 4^{\circ}$ geographical degree grid system for the transition to operations. The resolutions of the polar stereographic grids are such that grid spacing (in this case $\sim 18 \mathrm{~km}$ ) are roughly similar to that of the low-latitude grid at the grid boundaries, noting that this boundary is the latitude where both have the highest resolution. One advantage of the IRI system is that each grid has more uniform grid spacing (in terms of real distances) than any alternative single-grid global system, which means that the limiting time step for CFL stability is larger, thus making the system more efficient. More details about the specifics of these grids can be found in [37].

Data assimilation was a recent enhancement to the operational WW3 model runs at FNMOC bringing in satellite altimeter measurements of significant wave height [38]. The latest application of NCODA [30] uses WW3 software libraries to directly access files and interpolate fields.

One of the main purposes of the U.S. Navy operational global WW3 model simulations is to provide boundary conditions to the nested wave model simulations, in support of various missions throughout the globe. The global model was also set up to supply boundary conditions to the operational SWaSS model. For the purposes of the present study, the model was run for a period of three months, over which time full spectral boundary conditions were output every three hours, with 35 directional bins and 31 frequency bins starting at $0.0418 \mathrm{~Hz}$ and ranging up to $0.7295 \mathrm{~Hz}$, the same specification as the state variables.

In addition, WW3 can write the spectra in a reduced form consisting of the five first moments of the spectra based on a limited set of Fourier coefficients. These reduced spectra are expandable to approximately the original full spectral values using techniques described in Section 4.2.

\subsection{Simulating Waves in the Nearshore (SWAN)}

The spectral SWAN model was coupled hourly with a Delft3D [39], depth-averaged hydrodynamic model. The details of the hydrodynamic model are described in [27] and [4], respectively, for the tidal and storm tidal water level calibration and validation. The combined modelling system is called the SWaSS model. The regional SWAN numerical grid extent (shown in Figure 1) extends from $24^{\circ} \mathrm{S}$ to $38^{\circ} \mathrm{S}$ and $12.5^{\circ} \mathrm{E}$ to $38^{\circ} \mathrm{E}$ at $1 / 16$ th geographical degree resolution. High-resolution nested numerical grids were developed for all the coastal port locations (refer to Figure 1). These nests were developed at 1/48th-degree resolution with local refinements down to between $700 \mathrm{~m}$ and $1 \mathrm{~km}$ resolution at measurement locations. All the computational SWAN grids were curvilinear and orthogonal. The extent of the grid depends on its relative distance from steep changes in location bathymetry. SWAN version 40.72 is currently used in the SWaSS model with basic physical parametrisations 
describe in Table 2. Both the directional and frequency bins (or resolutions) were set to 36 with the frequencies ranging from 0.05 to $1 \mathrm{~Hz}$.

Ref. [40] made use of a similar coupled SWAN model setup for the Dutch Continental Shelf Model (DCSM). They employed the Van der Westhuysen wind growth and source term settings. In the present study two whitecapping source term formulations were investigated, as listed in Table 2 . The spectrally averaged wave steepness model of [41] has a tendency to over-predict significant wave heights in the presence of locally generated wind waves in the presence of swell signals (mixed seas) [41] and was also evident in the present study (as elucidated in Section 6). The uncoupled (from swell energy) local estimation of wind-sea whitecapping model presented by [42,43] is the second model.

Table 2. Summary of physical parametrization setting for SWAN 40.72, used in the present study.

\begin{tabular}{|c|c|c|}
\hline $\begin{array}{c}\text { SWAN } 40.72 \\
\text { (3rd-Generation Model) }\end{array}$ & Model & Additional Information \\
\hline Open boundaries & WW3 Global & NRL model \\
\hline Meteorological forcing & Down scaled Unified Model & SAWS operational model \\
\hline Bottom Friction & Madsen [44] & $\mathrm{K}_{\mathrm{n}}=0.05 \mathrm{~m}$ \\
\hline Depth induced breaking & Battjes [45] & $\begin{array}{l}\text { Alpha (dissipation) }=1 \\
\text { Gamma (breaker) }=0.8\end{array}$ \\
\hline \multirow[t]{2}{*}{ Whitecapping } & Komen [41] & $\begin{array}{c}\text { Exponential growth, } \\
\text { Dissipation rate coeff. }(\mathrm{Cds})=2.36 \\
\times 10^{-5} \\
\text { Pierson-Moskowitz spectrum } \\
\text { wave steepness }=3.02 \times 10^{-3} .\end{array}$ \\
\hline & Van der Westhuysen [42] & $\begin{array}{l}\text { Non-linear saturation-based } \\
\text { whitecapping. }\end{array}$ \\
\hline
\end{tabular}

Due to the extent of the regional SWAN domains, all models were executed in non-stationary mode. In Figure 2 some examples of the operational output from SWaSS are given. The enclosures of each of these nested domain (used in the present study) is given in Figure 1 Local refinements were also used in the vicinity of the in situ buoy locations. 


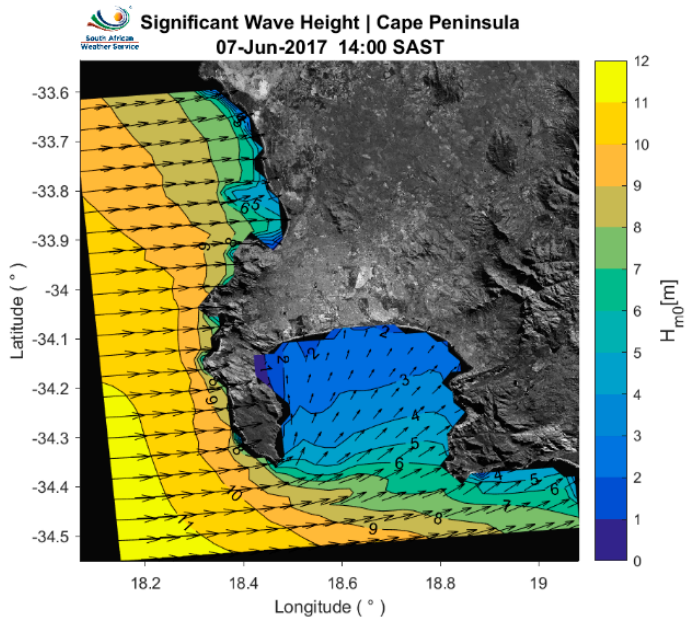

Init. 01-Jun-2017 00:00 UTC

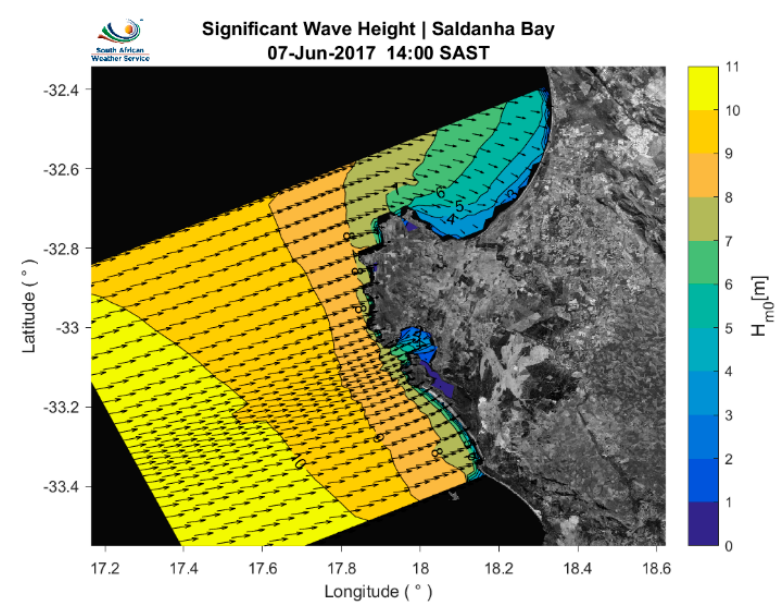

Init. 01-Jun-2017 00:00 UTC

(a)

(b)

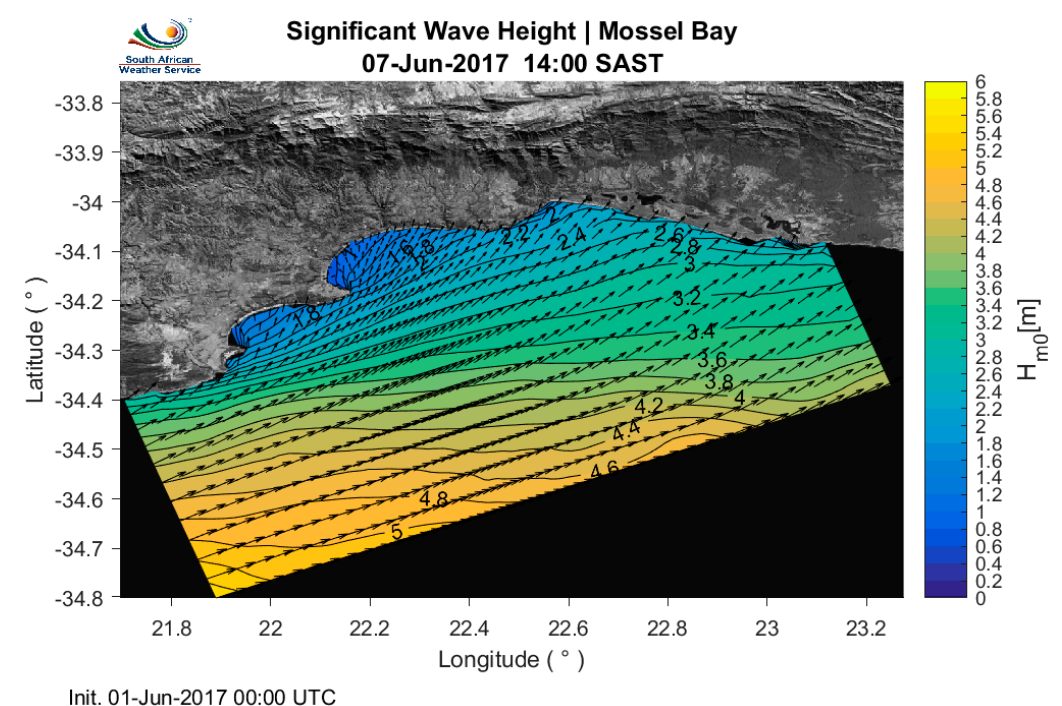

(c)

Figure 2. Example output from the SWaSS operational systems. Each of these is an example of the nearshore, high resolution, nested domains. Local refinements are also applied in the immediate vicinity of each buoy location. (a) Cape Town (CT) nested domain, (b) Saldanha Bay (SB) nested domain, and (c) the Mossel Bay (MB) nested domain.

\section{Boundary Spectral Reconstruction}

\subsection{Singular Partition Reconstruction}

Single partition reconstruction is one of the most common ways of using and saving global wave datasets for localized models. The spectrum is reduced to a single set of representative conditions. These are usually the significant wave height, peak or mean period, peak or mean direction and a directional spreading value. Using well-known wave spectrum shapes (like the Joint North Sea Wave Project (JONSWAP)), these parameters can be reconstructed into a representative spectrum. The age or peakedness of the spectrum can also be varied via the peak enhancement factor $(\gamma)$ [46]. Typically, a single $\gamma$ is estimated for the whole domain, as well as a singular directional distribution. For small coastal domains, this is usually a reasonable assumption. For regional domains, this might be a bad assumption due to the heterogeneity of the wave and atmospheric conditions on the boundary. 
In Section 6.2, the regional comparisons of a single partition, parameter, or JONSWAP spectrum are compared with the same model forced with fully spectral WW3 boundaries. The $\gamma$ was chosen as 2.5 [47] and the directional spreading a constant $25^{\circ}$. This is the current implementation of the wave forecasts predicted in SWaSS. The $\gamma$ and directional spreading is spatially and temporally constant.

\subsection{Five-Moment Reconstruction}

The directional wave spectrum $S(f, \theta)$ quantifies the wave energy distribution as a function of wave frequency, $f$, and direction, $\theta$, and is expressed as the product of the omni-directional wave spectrum $E(f)$ and the directional distribution function $D(f, \theta)$ as:

$$
S(f, \theta)=E(f) D(f, \theta)
$$

where the directional distribution can be decomposed into a Fourier series expansion [48]:

$$
D(f, \theta)=\frac{1}{\pi}\left\{0.5+\sum_{n=1}^{\infty}\left[a_{n} \cos (n \theta)+b_{n} \sin (n \theta)\right]\right\},
$$

and $a_{n}$ and $b_{n}$ are the Fourier coefficients of the $n t h$ harmonic component and can be computed as:

$$
\begin{gathered}
a_{n}=\int_{0}^{2 \pi} D(f, \theta) \cos (n \theta) d \theta, \\
b_{n}(f)=\int_{0}^{2 \pi} D(f, \theta) \sin (n \theta) d \theta .
\end{gathered}
$$

In practice, [48] proposed the use of the first two Fourier harmonics to approximate the directional spreading as:

$$
D(f, \alpha) \approx \frac{1}{\pi}\left\{0.5+r_{1} \cos \left(\alpha-\alpha_{1}\right)+r_{2} \cos \left[2\left(\alpha-\alpha_{2}\right)\right]\right\}
$$

where $\alpha$ follows the meteorological convention that the direction from which waves come measured clockwise from the north, and the coefficients $r_{1}, r_{2}, \alpha_{1}$ and $\alpha_{2}$ are computed as:

$$
\begin{gathered}
r_{1}=\sqrt{a_{1}^{2}+b_{1}^{2}}, \\
r_{2}=\sqrt{a_{2}^{2}+b_{2}^{2}} \\
\alpha_{1}=3 \pi / 2-\tan ^{-1}\left(b_{1} / a_{1}\right), \\
\alpha_{2}=3 \pi / 2-\frac{1}{2} \tan ^{-1}\left(b_{2} / a_{2}\right) .
\end{gathered}
$$

Several data-adaptive methods have been developed for providing higher directional resolution using the one-directional frequency spectra, and these coefficients, $r_{1}, r_{2}, \alpha_{1}$ and $\alpha_{2}$, of the Fourier series. The Maximum Likelihood Method (MLM) [49] and the Maximum Entropy Method (MEM) [50] are widely used in practice [51], providing more discussions for the data-adaptive methods. In the present study, we show the application of WW3 output, omni-directional wave energy spectrum and the Fourier coefficients $r_{1}, r_{2}, \alpha_{1}$ and $\alpha_{2}$ (with the above equations) to produce directional spreading and directional wave spectra with high directional resolution by means of MEM or MLM.

\section{Methodology}

Both regional and in situ validation were performed. Six scenarios were constructed as listed in Table 3 Each scenario aimed at investigating both the influence of the whitecapping formulation and the various boundary conditions described in Section 4 . Each scenario was compared with measurements 
at the nine coastal wave rider buoy locations described in Section 2.2. The results of these comparisons are given in Section 6. To be able to understand the spatial distribution of these scenarios, difference map plot comparisons were produced. Each difference plot was made in comparison with the fully spectral model boundary conditions simulation, given by M3 and M4 in Table 3. Based on these results, recommendations for the operational SWaSS model's wave forecasting component are presented.

Table 3. Description of the various permutations used in the present study to investigate the best combinations of whitecapping formulation and swell boundary conditions.

\begin{tabular}{|c|c|c|c|c|c|}
\hline \multicolumn{2}{|c|}{ M1 } & \multicolumn{2}{|c|}{ M2 } & \multicolumn{2}{|c|}{ M3 } \\
\hline Spectrum & Whitecapping & Spectrum & Whitecapping & Spectrum & Whitecapping \\
\hline JONSWAP & $\begin{array}{c}\text { van der } \\
\text { Westhuysen }\end{array}$ & JONSWAP & Komen & Fully Spectral & $\begin{array}{c}\text { van der } \\
\text { Westhuysen }\end{array}$ \\
\hline \multicolumn{2}{|c|}{ M4 } & \multicolumn{2}{|c|}{ M5 } & \multicolumn{2}{|c|}{ M6 } \\
\hline Spectrum & Whitecapping & Spectrum & Whitecapping & Spectrum & Whitecapping \\
\hline Fully Spectral & Komen & 5-parm & $\begin{array}{c}\text { van der } \\
\text { Westhuysen }\end{array}$ & 5-parm & Komen \\
\hline
\end{tabular}

The focus of the present study is on the relative influence of various boundary conditions and established whitecapping formulations on the produced wave field evolution and the ultimate coastal wave response. The validation presented in the present study is well aligned with published validation principles (e.g., [52,53]).

In this study, the centred-Root-Mean-Square Difference (cRMSD) is given by:

$$
c R M S D^{2}=\sum_{n=1}^{N}\left((p-\bar{p})-(r-\bar{r})^{2}\right) / N
$$

where $p$ is the predicted values, $r$ is the reference values, and $N$ is the total number of values being compared. The bias is given as the difference between the mean predicted minus the mean reference data. In the present study, the reference data will be the measured wave rider buoy or altimetry data. Data sets described as normalized were normalized with regard to the standard deviation of the reference field.

\section{Results and Discussion}

The austral winter months (June, July and August (JJA)) of 2017 were used in the present wave field evolution investigation. During June, a mid-latitude cyclone, locally referred to as the Cape Storm, caused widespread disruptions on the South African southwestern and southern coasts. Significant wave heights in excess of $12 \mathrm{~m}$ were recorded at the Slangkop wave rider buoy (refer to Table 1 and Figure 3) and contributed to significant storm surge water levels [4]. 


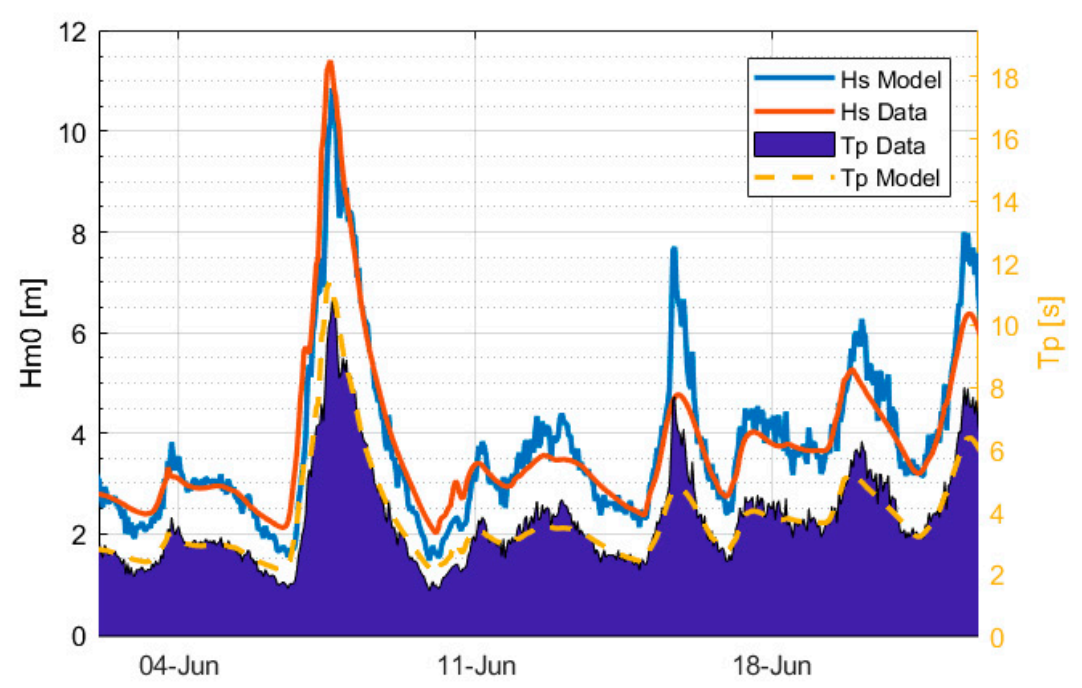

Figure 3. Time series comparison of modelled vs. measured significant wave heights (left axis) and peak periods (right axis) during June 2017 for scenario M3.

The wave conditions during JJA were thus characterized by both swell and locally generated wind seas and were deemed adequate for evaluating the SWAN model performance and sensitivity, similar to a study performed at Nova Scotia, Canada, where an extra-tropical storm (Nicole) was used to test their local SWAN model sensitivities [43]. Due to their small computational domain, they also investigated the relevance of stationary versus non-stationary computations. The coupled water levels during storm events significantly influenced the wave model accuracy during storm conditions and vice versa [4]. This is especially true in shallower water or when waves move over shallow areas like the Agulhas Bank.

\subsection{In situ Comparisons}

The buoys listed in Table 1 were used for nearshore validation. In Figure 4, the Taylor diagram [54] comparisons of all the model scenarios are presented for a few selected coastal wave rider buoy locations. All statistical correlation definitions are provided in Appendix C. Sites where chosen to represent each of the three major coastlines (western, southern, and eastern coasts of South Africa). FH Platform is also the location furthest south on the edge of the Agulhas Bank (refer to Table 1 and Figure 1). A useful manner of interpreting these figures is by remembering that even model scenarios numbers (M2, M4 and M6) were executed with the Komen whitecapping formulation while odd numbers (M1, M3 and M5) were executed with the Van der Westhuysen formulation. For the full model performance statistics (including peak period and direction), for all the coastal measurement locations and model configuration scenarios, please refer to Appendix A. 


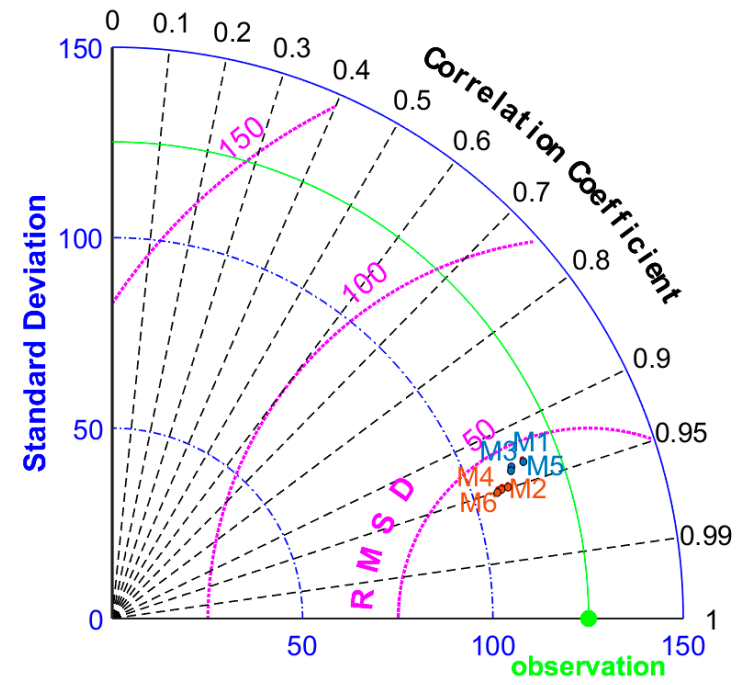

(a)

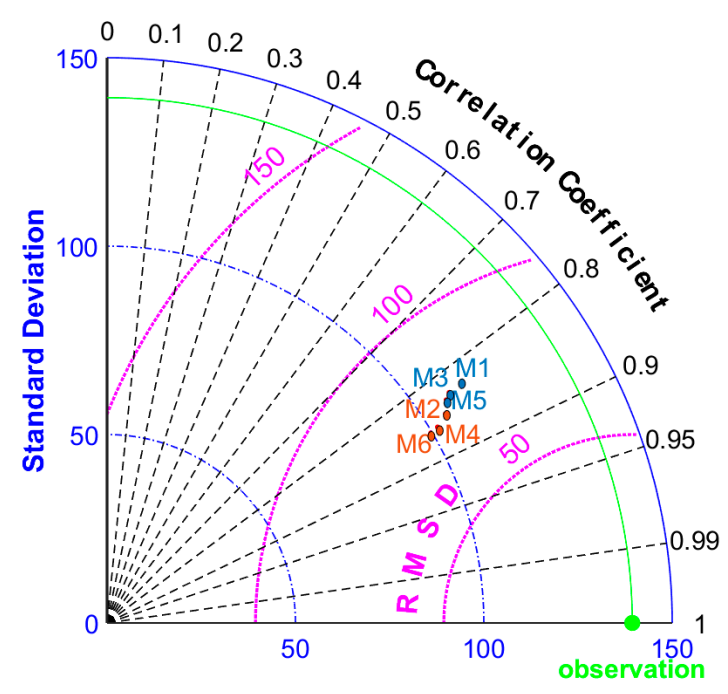

(c)

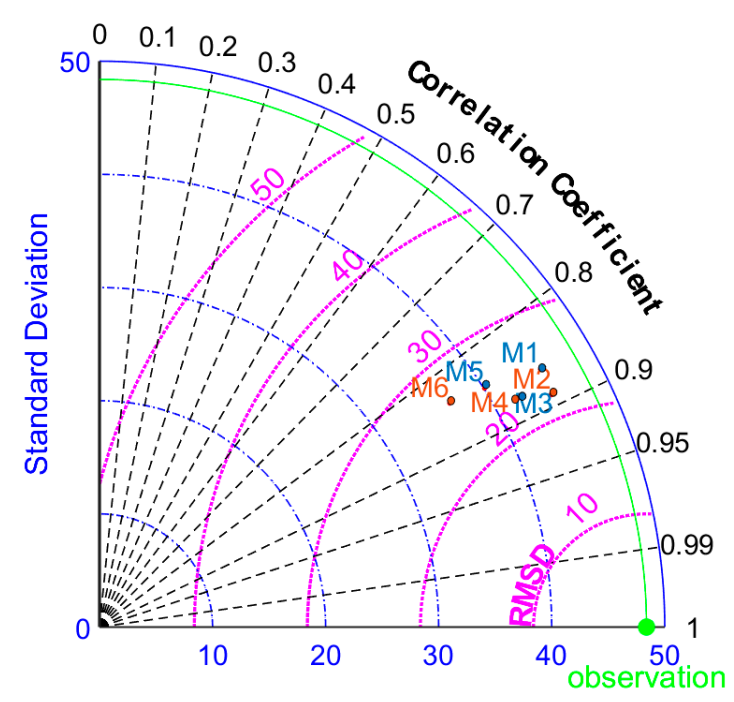

(b)

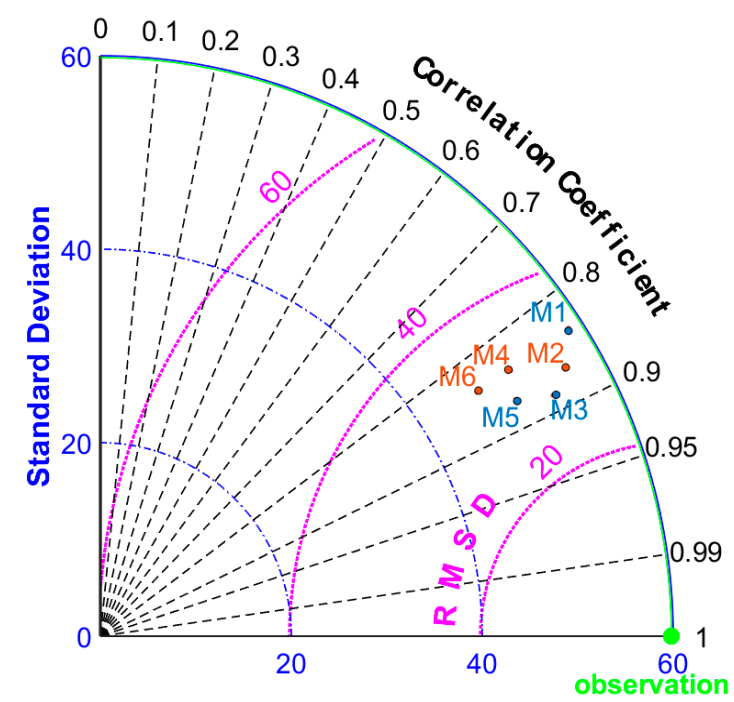

(d)

Figure 4. Selected Taylor diagrams $[54,55]$ illustrating significant wave height $\left(\mathrm{H}_{\mathrm{m} 0}\right)$ model performance as a function of centered-Root-Mean-Square Difference (cRMSD), the correlation coefficient and standard deviation [54]. Units are in centimetres [cm] and are situated at the following locations: (a) Cape Town (CT), (b) Port Elizabeth (PE), (c) FH Platform (FHP), and (d) Richards Bay (RB). These results are for JJA 2017. The scenarios (M1 to M6) are prescribed in Table 3.

The various combinations of physics and spectral boundary conditions given in Table 3 produce varying accuracies around the South African coastline. On the western coast, the results are similar. All west coast scenarios congregate with high correlation values (between 0.90 and 0.96). The Saldanha Bay buoy is located within the bay and thus experiences a degree of sheltering, as presented by the lower standard deviation (refer to Appendix B). Figure 4a indicates the large standard deviations at Cape Town. This is due to the geographical location of the Cape Town (Slangkop) wave rider buoy. Due to the narrow continental shelf, the deep southwesterly Southern Ocean swell loses little of its energy as it propagates towards the continent (and hence the high correlation values). The same cannot be said of the areas adjacent to the continental shelves as large swell will lose some of its energy over these shallower regions [56]. The dominant wave direction for most of the South African coastline is from the southwest, thus rendering the western and southwestern coasts exposed $[5,23]$. The full wave 
climatology is provided in Appendix B. Within the scenarios, there does exist a measure of grouping. At Cape Town, the groupings are divided by whitecapping formulation, with the Komen formulation performing slightly better for all boundary conditions. At Saldanha Bay, the groupings are based more on the type of boundary conditions. Here, Komen again performed marginally better with the fully spectral boundary conditions. This is an indication that on the western and southwestern coasts, the wave climate is southwesterly swell driven, and the boundary reconstruction method or white capping formulation is less important in the nearshore. It should be noted that an improved physics description of the locally and offshore generated wind waves might lead to a better overall prediction of the wave climate.

On the southern coast, the FH platform results in large standard deviations due to its proximity to the Agulhas Bank shelf edge. On the southern coast, the various scenarios perform differently, but with the Komen whitecapping formulation performing the best. In both cases, correlation values between 0.8 and 0.9 are obtained. The fully spectral boundary conditions provide slightly better results at FH Platform (refer to Figure 4c), but in general all the model predictions are similar. On the southeastern coast, all correlations are again above 0.8 , with measurements at Port Elizabeth (refer to Figure $4 \mathrm{~b}$ ) performing slightly better. The spread of predictions is mostly related with the modelled standard deviation similar to the southern and eastern coasts results. The Komen whitecapping formulation once again performed slightly better. At Durban, the model correlations performed with correlations values under 0.8 . This might be due to neglecting the complex wave-current interaction in the current spectral wave model implementation as noted by [23]. Richards Bay (refer to Figure 4d) produced high correlation and adequate cRMSD values. In general, the largest variation was observed along the standard deviation axis. The Komen formulation (refer to Table 2) gave the best results, while the boundary condition specification did not produce significant variations in the results. The JONSWAP boundary reconstruction method performed adequately, while the range of cRMSD values compared well with other modelled wave climate validations from published literature around the world (e.g., India [6], The Netherlands [40] and southwestern Australia [57]). The India focused model produced RMSD values ranging between 0.15 and $0.24 \mathrm{~m}$, even though extreme $\mathrm{H}_{\mathrm{m} 0}$ events had a tendency to be underpredicted [6]. The Dutch coast operational system produced $\mathrm{H}_{\mathrm{m} 0}$, RMSD values ranging from 0.2 to $0.6 \mathrm{~m}$, depending on the season [40]. The largest errors were observed during winter months, but the normalized RMSD indicated a stable error estimation.

Another aspect to investigate the performance of the model is via the normalized bias. Figure 5 presents the normalized target diagrams [58] for all the in situ measurement locations for JJA. The model scenarios were divided per coastline grouping (similar locations). An effective manner of interpreting Figure 5 is to access the model performance with regard to its relative position to the center of the plot. 


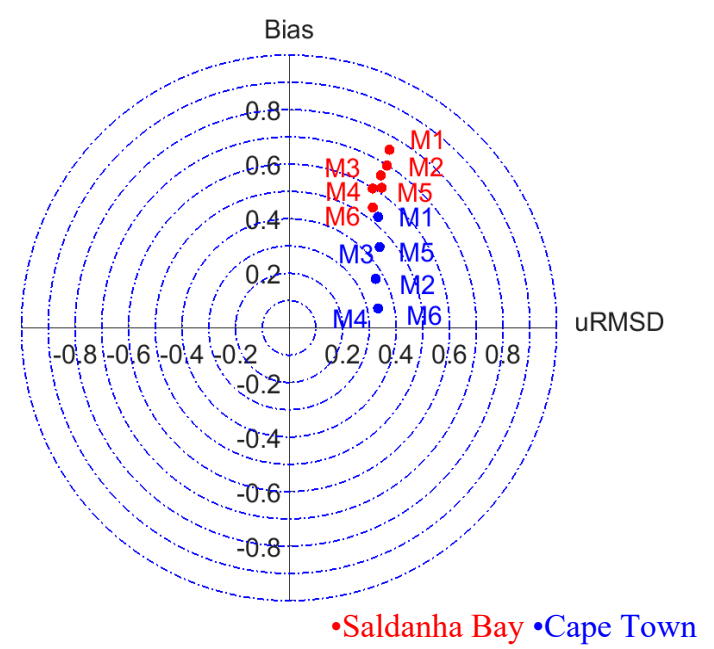

(a)

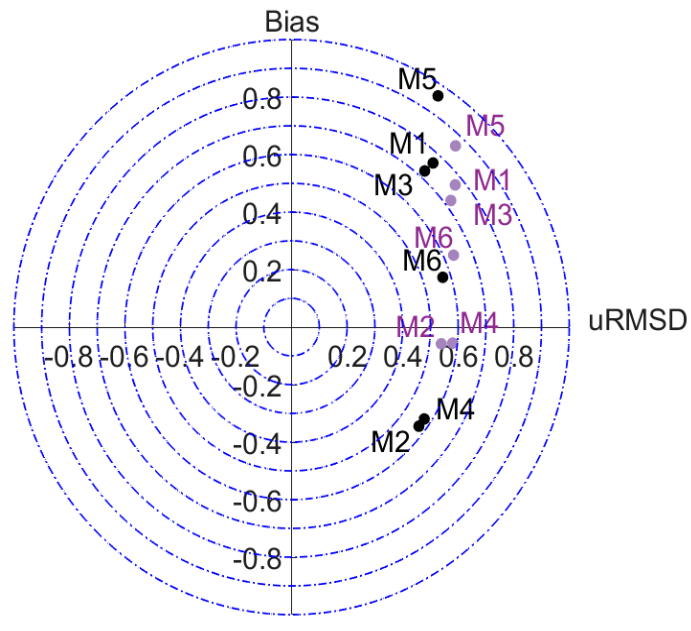

•Port Elizabeth $•$ East London

(c)

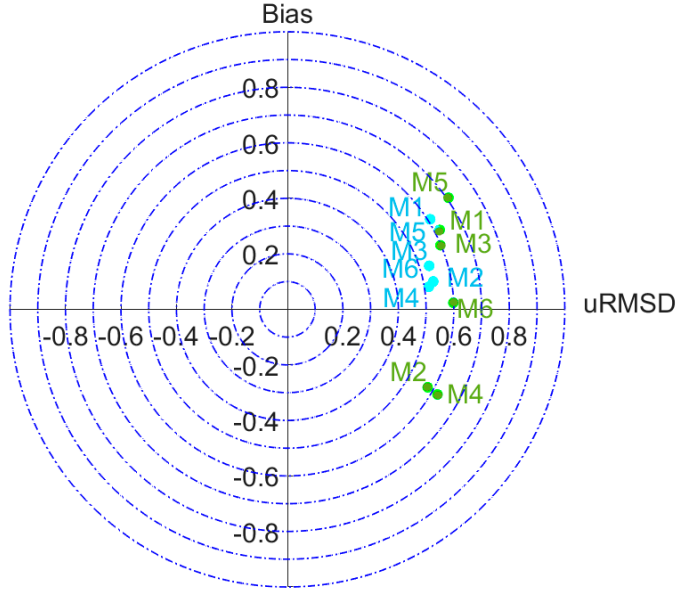

-Mossel Bay $•$ FH Platform

(b)

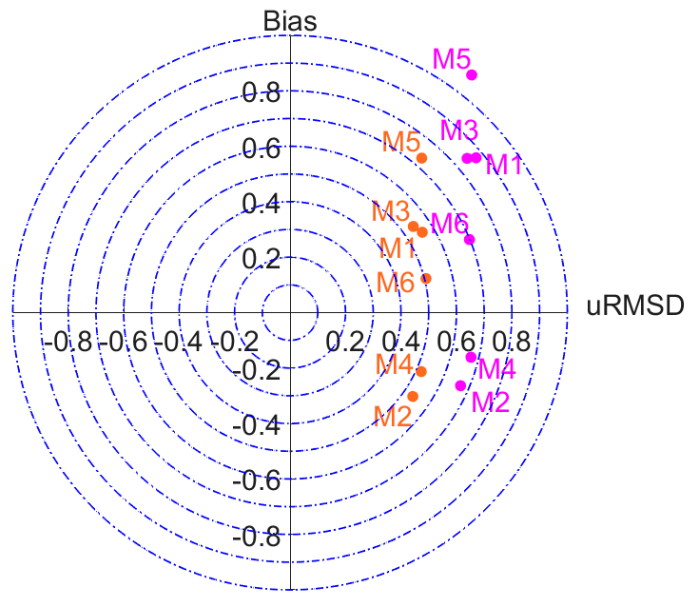

-Durban •Richards Bay

(d)

Figure 5. Target diagrams according to [58] with normalized, unbiased, Root-Mean-Square Difference (uRMSD) $\mathrm{H}_{\mathrm{m} 0}$ against normalized bias for (a) the western coast, (b) the southern coast, (c) the southeastern coast, and (d) the eastern coast.

Here, the Komen whitecapping simulations performed the best at Cape Town, together with fully spectral boundary conditions and the five-parameter reconstruction method. Saldanha Bay performed worse and probably due to the sheltered nature of the wave rider buoy. The model performance spreading was also less varied compared to the results at Cape Town. On the south coast, the model performance presented varied biases. At Port Elizabeth, the Komen whitecapping formulation performing the best, with M4 and M6 within the 0.6 target segment. East London presented a similar result pattern. On the eastern coast, the model performed better at Richards Bay than at Durban, but with both locations revealing a similar validation pattern. In both cases, the Komen formulation performed best, with only scenario M5, at Durban and East London, performing worse than most simulations.

\subsection{Regional Altimetry Validation}

The regional validation described in Sections 2.3 and 5 are presented in Figure 6 and Table 4 . For the regional model performance, the Van der Westhuysen whitecapping formulation outperforms 
the Komen formulation. Whitecapping formulations ultimately established a relationship between wind input driven dynamics and quadruplet wave interactions [59]. Ref. [59] reported some limitation of the default SWAN (40.51) model. Calibrating the model with regard to bottom friction and breaking parameters presented some significant improvement. Among these were an $\mathrm{H}_{\mathrm{m} 0}$ bias reduction from $-3 \%$ to $-1 \%$. Within the experimental setup of [59], they found that the Van der Westhuysen whitecapping formulation performed well under storm conditions in tidal inlet seas. They did, however, notice some aspects of the model that required further investigation, including the penetration of low-frequency wind waves into the inlet seas [59]. Van der Westhuysen mentioned and improvement over the Komen whitecapping formulation in depth limited wave growth simulations. Even with these improvements, wave heights and periods were underestimated by approximately $12 \%$ and $10 \%$, respectively, in the Wadden Sea interior. According to [60], whitecapping is still one of the most prominent tuning factors in spectral wave modelling, even though it is not limited to shallow or enclosed ocean considerations. In Figure 6, the relative difference between the Van der Westhuysen and Komen whitecapping model are given for the month of June 2017, with fully spectral boundary conditions.

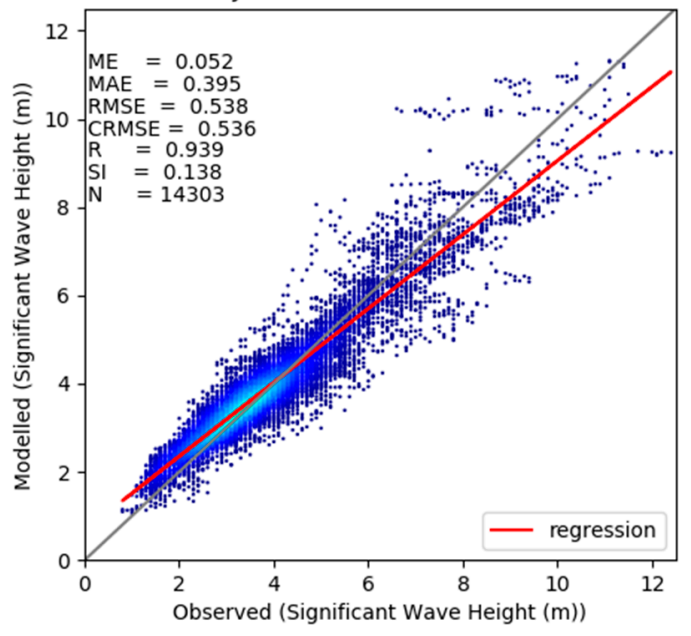

(a)

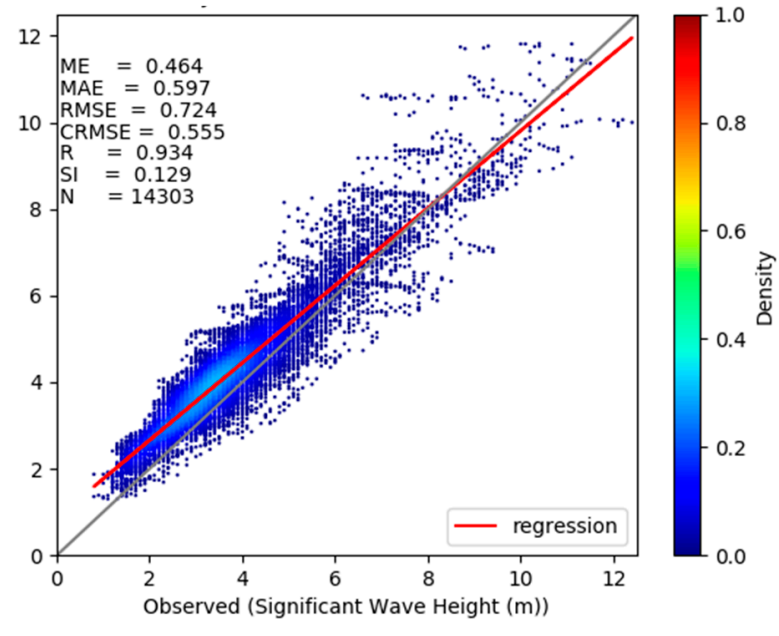

(b)

Figure 6. Correlation between co-located Altimetry measurements and the regional SWAN model results for (a) June M3 and (b) June M4.

The Komen formulation implicitly made the assumption that the wave field was wind driven (wind seas) [53]. Once one or more swell signals are present, the assumption within the Komen model starts to lose its usefulness, and thus its intended meaning [53]. This could be the explanation for the difference in the results between the in situ measurements in Section 6.2 and the regional validation presented in the present section. All the in situ buoys were in coastal seas, which would be closer to the assumptions presented by the Komen whitecapping model. The Komen model tends to overpredict wind seas and underpredict swell seas (in a mixed seas state due to dissipation rates) [53]. This behaviour is evident in Figure 6, where the regression lines for a Van der Westhuysen (M3) and Komen (M4) model are given.

In the coastal regions, bottom friction is also an important calibration parameter, as it is intertwined with the other wave energy sources and sinks. The [44] model is described as a "sophisticated eddy viscosity model" [53] and was employed in the present study. Other widely used formulations include the [61] prediction of shallow-water spectra. [26] performed similar investigations in The Canadian Beaufort Sea. They also reported that the Van der Westhuysen formulation performed better than Komen in deep water. In shallow water, they found that either formulation performed adequately and that $\mathrm{H}_{\mathrm{m} 0}$ was not that sensitive to either formulation. They also reported limited sensitivity to bottom friction and the inclusion of triad mechanisms [26]. 
In Table 4, the RMSD, centred-Root-Mean-Square Difference (cRMSD), Scatter Index (SI) and correlation coefficient $(\mathrm{R})$ for all the regional model comparisons are given. The fully spectral boundary conditions scenarios performed the best with the Komen formulation. Unlike the formulation by Komen, the Van der Westhuysen formulation calculates wind sea whitecapping locally in the spectrum and uncoupled from the swell energy [42]. Thus, either the swell signal has an important influence on the dissipation of the wind seas (Komen), or it has little importance (Van der Westhuysen) [42]. As also indicated by the results presented here, the composition of the predicted sea state must be considered in choosing the appropriate whitecapping formulation.

Table 4. Regional wave model performance compared with the co-located altimetry measurements (refer to Section 2.3) per investigated month. Each model configuration (M1 to M6) is described in Table 3.

\begin{tabular}{ccccccccccccc}
\hline Month & \multicolumn{4}{c}{ June } & \multicolumn{4}{c}{ July } & \multicolumn{4}{c}{ August } \\
\hline Stats & RMSD & cRMSD & SI & $\boldsymbol{R}$ & RMSD & cRMSD & SI & $\boldsymbol{R}$ & RMSD & cRMSD & SI & $\boldsymbol{R}$ \\
M1 & 0.56 & 0.55 & 0.14 & 0.93 & 0.55 & 0.47 & 0.12 & 0.94 & 0.49 & 0.48 & 0.14 & 0.93 \\
M2 & 0.79 & 0.61 & 0.13 & 0.93 & 0.89 & 0.51 & 0.12 & 0.93 & 0.49 & 0.48 & 0.14 & 0.92 \\
M3 & 0.54 & 0.54 & 0.13 & 0.94 & 0.45 & 0.43 & 0.12 & 0.94 & 0.45 & 0.45 & 0.13 & 0.94 \\
M4 & 0.72 & 0.56 & 0.13 & 0.94 & 0.67 & 0.46 & 0.12 & 0.94 & 0.45 & 0.45 & 0.12 & 0.94 \\
M5 & 0.59 & 0.57 & 0.14 & 0.94 & 0.49 & 0.45 & 0.12 & 0.94 & 0.50 & 0.46 & 0.13 & 0.94 \\
M6 & 0.80 & 0.57 & 0.13 & 0.94 & 0.75 & 0.45 & 0.11 & 0.94 & 0.66 & 0.48 & 0.12 & 0.93 \\
\hline
\end{tabular}

In general, the scatter plots of both June and August 2017 indicated very similar behaviour, while July presented slightly different results. During July, the Komen model produced a near constant bias, while the Van der Westhuysen model produced high correlation values. The behaviour between the various model runs were similar per month per whitecapping formulation.

\subsection{Spatial Variations}

The different boundary conditions have direct consequences on the introduction of energy into the regional domain. If the directional spreading is too broad or too narrow, energy will dissipate into the regional at an incorrect tempo. This might result in the underestimation of deep-sea swell signals that are not generated by local winds. In Figure 7, the spatial comparison of all modelled scenarios for June 2017 is compared with the fully spectral boundary condition scenario. 


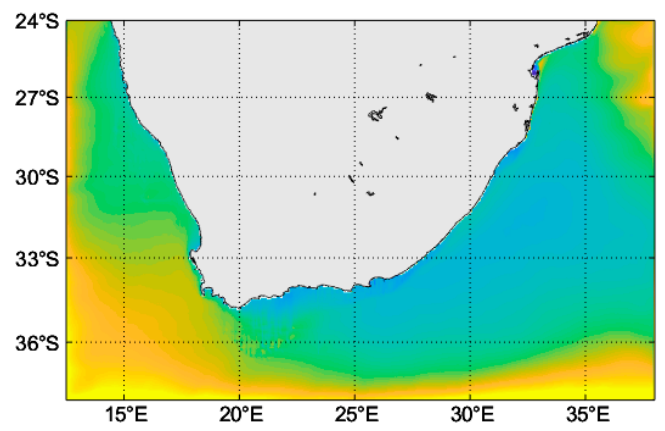

(a)

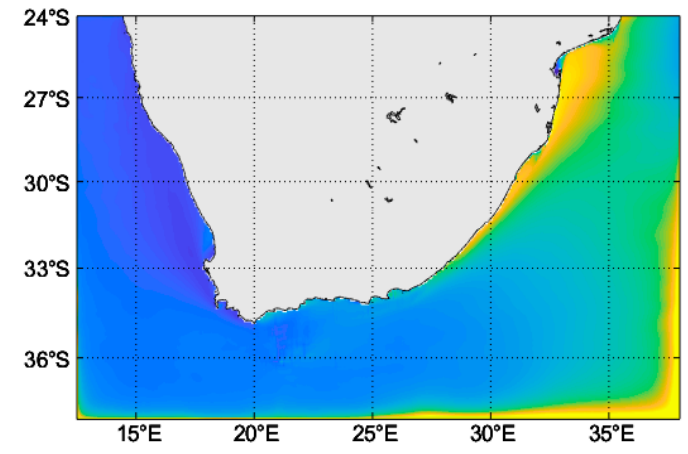

(c)

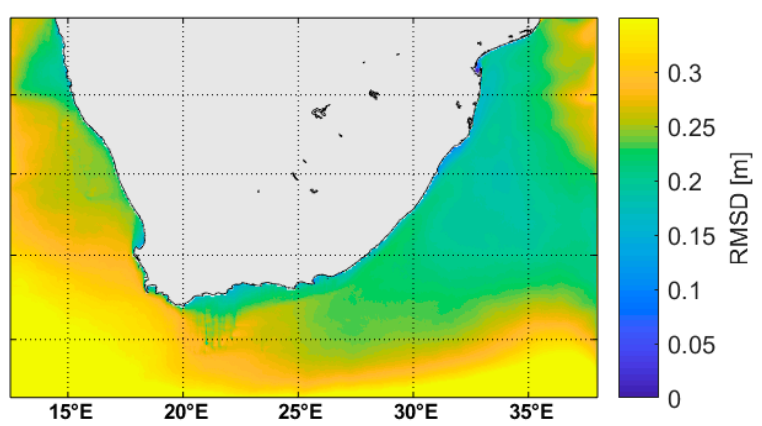

(b)

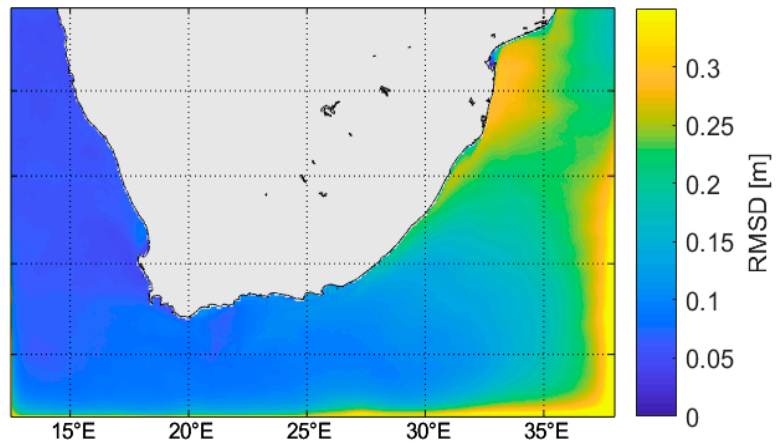

(d)

Figure 7. Spatial RMSD maps for June 2017. Here all the reconstructed boundary condition scenarios are compared with the fully spectral output boundary conditions. The particular scenarios are (a) M1, (b) M2, (c) M5, and (d) M6.

From Figure 7a,b, it is given that the parameterized JONSWAP boundary reconstruction method differs most. Together with the boundary conditions, the Komen whitecapping formulation produced the largest differences in the open ocean. Each scenario compared the same whitecapping formulation, implying that the mixed wave open ocean was clearly misrepresented with the Komen formulation. From the wave climatology presented in Appendix A, it is clear that South Africa's main wave approach direction is from the southwest, and due to this predominant swell signal, the errors produced by the JONSWAP reconstruction and the Komen formulation were the largest in the southwest. On the eastern coast, the RMSD values were lower due to the dominance of locally generated wind seas. Hence the dependence on the boundary conditions decreases. The long-period wave interactions with the continental shelf edge is also visible due to the differences in the scenarios. In Figure $7 c, d$ the map result followed a different pattern. Here, the reconstructions are generally performing well except on the southeast coast.

In general, the RMSD values on the continental shelves were low, indicating the dominance of locally generated wind waves. This could potentially also be the explanation for the differences in model accuracies when comparing the results to remotely sensed and in situ wave buoys, also noted by [27].

\section{Conclusions}

SAWS developed a regional wave and storm surge forecasting platform called the SAWS Wave and Storm Surge (SWaSS) model. The various components of this online coupled, marine forecasting system have been calibrated and validated, with the tidal dynamic described by [28] and the storm surge dynamics described by [4]. The operational flow, configuration and atmospheric forcing details are also described in [4]. The present study aimed to elucidate the accuracies associated with the wave 
component of SWaSS. The spectral wave model Simulating Waves in the Nearshore (SWAN) was used for this purpose. The regional model was implemented with a series of nested, high-resolution domains at nine South African ports. Even higher local resolutions were described in the immediate facility of in situ wave ride buoys, via local refinements. Both in situ and regional altimetry measurements were used in the validation of the wave model. Model sensitivities were investigated with regard to boundary conditions and whitecapping formulations employed. Similar to [26], the well-established formulations of Komen [41] and Van der Westhuysen [42] were investigated. In the near shore (in situ buoy locations), the Komen formulation marginally outperformed the Van der Westhuysen correlation. With the regional altimetry validation, the Van der Westhuysen formulation produced the best results. Thus, in general, the use of the Van der Westhuysen model is recommended. The main reason for this is because the latter correlation better solves the wind-sea spectral peak in the presence of swell signals [42].

Various boundary reconstruction methods were also investigated. The main motivation for this was due to the computational constraints a lot of public and private engineering and scientific institutes face. Parameter-based, reconstructed, spectral boundary conditions are commonplace and an acceptable standard due to the limited availability of free fully spectral boundary conditions (usually from larger, global spectral models (e.g., WW33)). The commonly used, unpartitioned, JONSWAP [46] spectral reconstruction method was compared with a five-parameter (or moment) reconstruction method, together with fully spectral boundary conditions, provided by the US Navy. The biggest differences were observed on the southeastern boundary of the model, aligned with the predominant swell direction. Here, the underlying assumptions in the reconstruction methods became clear, with the single partition reconstruction presenting the largest discrepancies, compared with the fully spectral boundary conditions. Either method is thus acceptable for regional and local wave modelling around South Africa, depending on the accuracies required for a particular study or investigation. Further increases in accuracies could be observed with various combinations of bottom friction and energy sources and sinks, such as the new physics described by [62].

Author Contributions: Conceptualization, C.R.; methodology, C.R.; software, C.R., M.A.B., D.W.W. and J.D.; validation, C.R., M.A.B., D.W.W. and J.D.; formal analysis, C.R., M.A.B., D.W.W. and J.D.; investigation, C.R.; resources, C.R., M.A.B., D.W.W. and J.D.; data curation, C.R., M.A.B. and J.D.; writing-original draft preparation, C.R.; writing-review and editing, J.D. and M.A.B.; visualization, C.R., M.A.B. and J.D.; supervision, C.R.; project administration, C.R.; funding acquisition, C.R. All authors have read and agreed to the published version of the manuscript.

Funding: This research was funded by the National Research Foundation of South Africa (Grant Numbers: 116359).

Acknowledgments: The authors would like to thank the South African Navy Hydrographic Office (SANHO) for providing high-resolution coastal bathymetry required for model calibration and validation. We acknowledge Transnet National Port Authorities (TNPA) for the in situ wave measurements used in the present study.

Conflicts of Interest: The authors declare no conflict of interest.

\section{Appendix A}

Here the seasonal wave climatology of the South African coastline is presented via wave roses per coastline. 

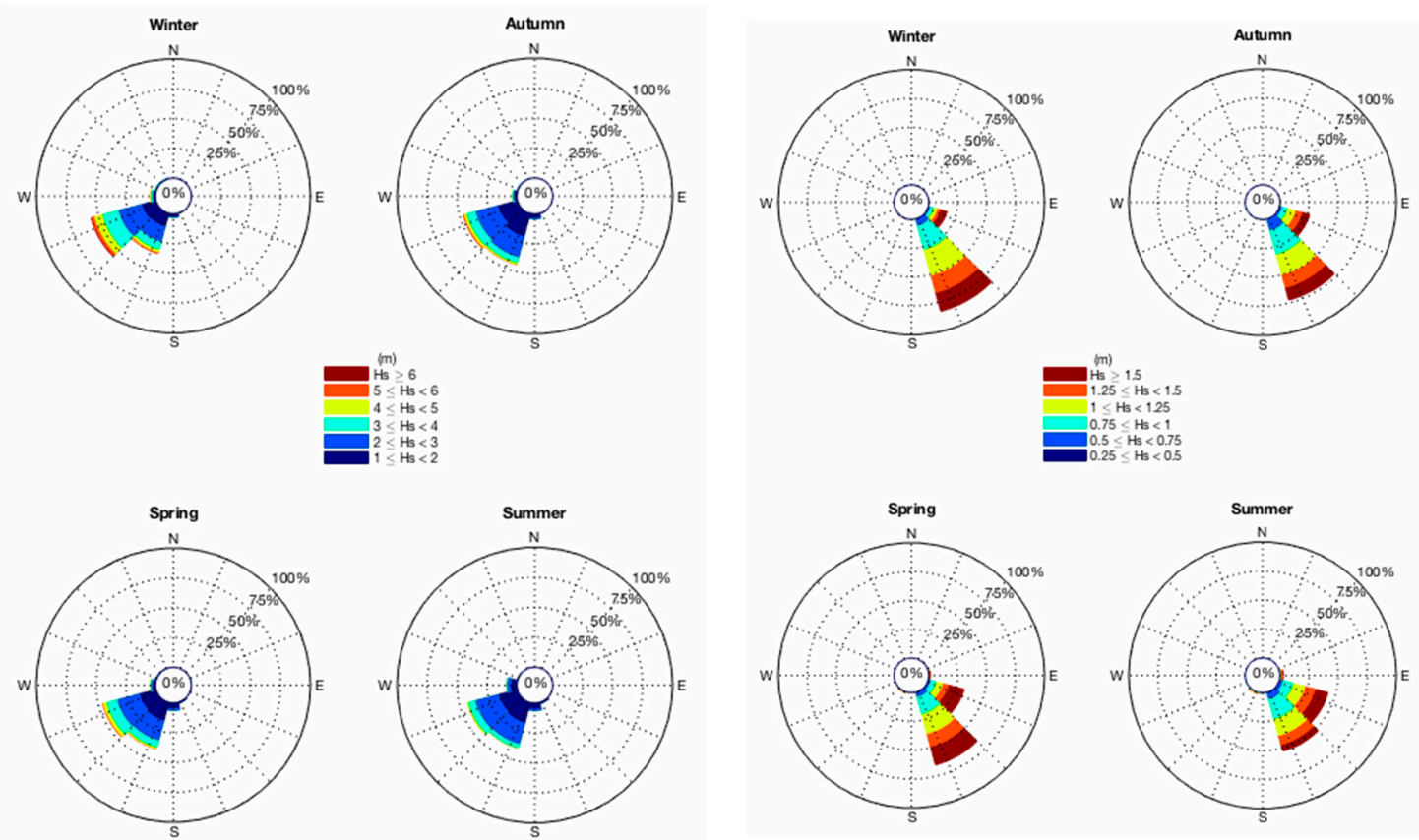

(a)
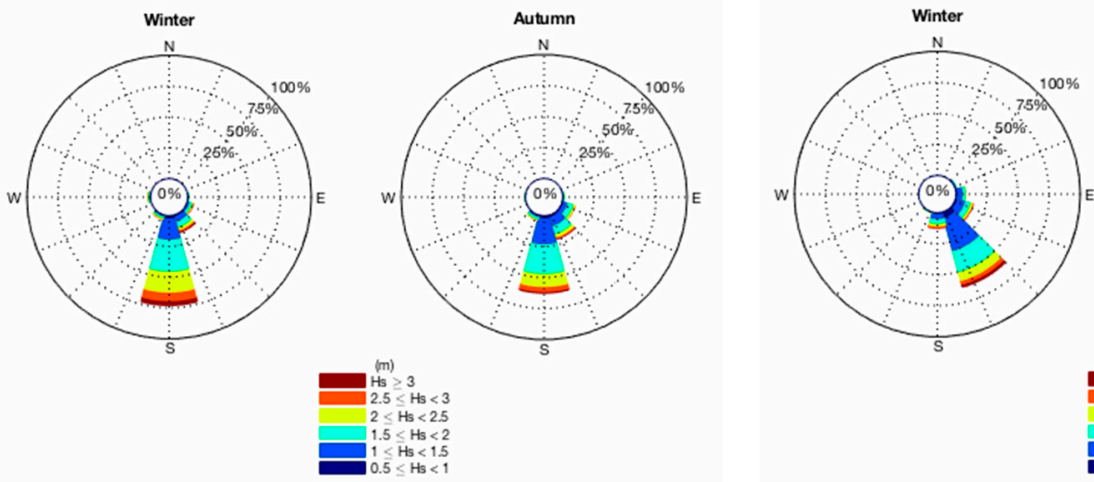

(b)
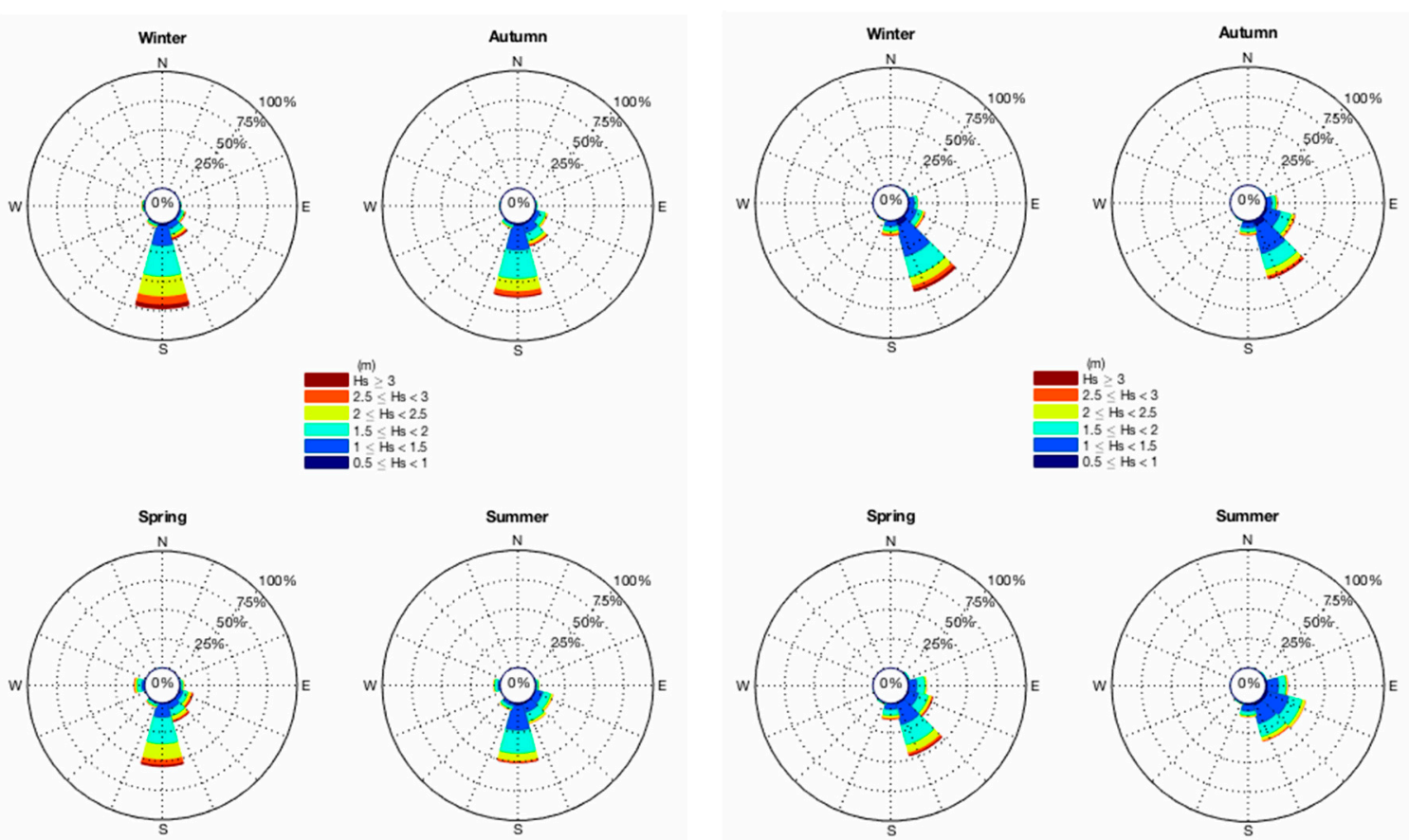

(c)

(d)

Figure A1. The $\mathrm{H}_{\mathrm{m} 0}$, seasonal, wave climatology for the South African coastline based on all available in situ wave rider buoy data at (a) Slangkop (Cape Town), (b) Port Elizabeth, (c) East London, and (d) Richards Bay.

\section{Appendix B}

Here, an extensive resource of model validation statistics is provided. Due to the limited local benchmarking data available in the open literature, these values could enable future studies with increasing accuracy and physical descriptions. In these statistics, reference is made to the [63] methods 
of assessing model performance (also refer to [4] for a description and reference to the newer model performance correlation presented by [64]). Statistical definitions are provided in Appendix C.

Table A1. Model performance statistics per coastal buoy location for JJA 2017, M1.

\begin{tabular}{cccccccccc}
\hline Station & \multicolumn{3}{c}{$\mathbf{H}_{\mathbf{m} \mathbf{0}}$} & & \multicolumn{3}{c}{$\mathbf{T}_{\mathbf{p}}$} & \multicolumn{3}{c}{ Peak Direction } \\
\hline ID & RMSD & Bias & Willmott & RMSD & Bias & Willmott & RMSD & Bias & Willmott \\
\hline CP & 0.39 & 0.09 & 0.97 & 1.55 & 0.09 & 0.76 & 16.79 & -1.35 & 0.54 \\
DB & 0.38 & 0.03 & 0.90 & 2.97 & -0.32 & 0.73 & 39.89 & -6.92 & 0.73 \\
MB & 0.39 & -0.20 & 0.85 & 1.40 & -0.22 & 0.87 & - & - & - \\
NG & 0.35 & -0.24 & 0.88 & 1.57 & -0.13 & 0.85 & 19.66 & 7.33 & 0.59 \\
OL & 0.42 & 0.02 & 0.91 & 2.05 & -0.56 & 0.75 & 37.46 & -9.08 & 0.53 \\
RB & 0.35 & -0.16 & 0.92 & 2.51 & -0.05 & 0.80 & 32.39 & -6.58 & 0.68 \\
SB & 0.49 & 0.40 & 0.88 & 1.77 & 0.07 & 0.76 & - & - & - \\
FA & 0.74 & 0.10 & 0.88 & 2.88 & 1.93 & 0.57 & 40.75 & -2.58 & 0.69 \\
\hline
\end{tabular}

Table A2. Model performance statistics per coastal buoy location for JJA 2017, M2.

\begin{tabular}{cccccccccc}
\hline Station & & $\mathbf{H}_{\mathbf{m} 0}$ & & & \multicolumn{3}{c}{$\mathbf{T}_{\mathbf{p}}$} & \multicolumn{3}{c}{ Peak Direction } \\
\hline ID & RMSD & Bias & Willmott & RMSD & Bias & Willmott & RMSD & Bias & Willmott \\
\hline CP & 0.72 & 0.66 & 0.85 & 1.06 & 0.16 & 0.81 & 13.71 & -0.68 & 0.76 \\
DB & 0.47 & 0.34 & 0.75 & 4.71 & -3.49 & 0.60 & 28.87 & -5.15 & 0.82 \\
MB & 0.33 & 0.22 & 0.82 & 2.66 & -1.07 & 0.54 & - & - & - \\
NG & 0.37 & 0.30 & 0.74 & 3.19 & -1.41 & 0.49 & 22.13 & 11.80 & 0.31 \\
OL & 0.55 & 0.39 & 0.78 & 2.03 & -0.41 & 0.72 & 31.80 & -7.22 & 0.35 \\
RB & 0.34 & 0.23 & 0.87 & 4.71 & -3.28 & 0.61 & 35.24 & -6.56 & 0.61 \\
SB & 0.58 & 0.52 & 0.76 & 1.08 & 0.37 & 0.81 & - & - & - \\
FA & 0.97 & 0.77 & 0.58 & 2.56 & 1.99 & 0.45 & 27.84 & -1.65 & 0.60 \\
\hline
\end{tabular}

Table A3. Model performance statistics per coastal buoy location for JJA 2017, M3.

\begin{tabular}{cccccccccc}
\hline Station & \multicolumn{3}{c}{$\mathbf{H}_{\mathbf{m} \mathbf{0}}$} & \multicolumn{3}{c}{$\mathbf{T}_{\mathbf{p}}$} & \multicolumn{3}{c}{ Peak Direction } \\
\hline ID & RMSD & Bias & Willmott & RMSD & Bias & Willmott & RMSD & Bias & Willmott \\
\hline CP & 0.40 & 0.04 & 0.96 & 1.17 & 0.05 & 0.84 & 12.56 & -1.35 & 0.73 \\
DB & 0.39 & 0.00 & 0.83 & 3.04 & -0.99 & 0.71 & 37.32 & -12.39 & 0.75 \\
MB & 0.34 & -0.18 & 0.84 & 1.40 & 0.05 & 0.83 & - & - & - \\
NG & 0.31 & -0.20 & 0.86 & 1.59 & 0.19 & 0.81 & 18.37 & 8.54 & 0.53 \\
OL & 0.41 & 0.00 & 0.88 & 1.75 & -0.50 & 0.79 & 38.18 & -11.19 & 0.42 \\
RB & 0.34 & -0.11 & 0.88 & 2.73 & -1.04 & 0.76 & 40.25 & -18.52 & 0.58 \\
SB & 0.44 & 0.37 & 0.88 & 1.36 & 0.24 & 0.81 & - & - & - \\
FA & 0.72 & 0.11 & 0.82 & 2.89 & 1.88 & 0.50 & 32.48 & 0.88 & 0.65 \\
\hline
\end{tabular}

Table A4. Model performance statistics per coastal buoy location for JJA 2017, M4.

\begin{tabular}{cccccccccc}
\hline Station & & $\mathbf{H}_{\mathbf{m} \mathbf{0}}$ & & \multicolumn{3}{c}{$\mathbf{T}_{\mathbf{p}}$} & \multicolumn{3}{c}{ Peak Direction } \\
\hline ID & RMSD & Bias & Willmott & RMSD & Bias & Willmott & RMSD & Bias & Willmott \\
\hline CP & 0.51 & 0.25 & 0.95 & 1.52 & 0.12 & 0.79 & 18.30 & -0.65 & 0.54 \\
DB & 0.58 & 0.46 & 0.77 & 4.59 & -3.32 & 0.48 & 40.98 & -15.92 & 0.72 \\
MB & 0.37 & 0.06 & 0.85 & 2.84 & -1.18 & 0.69 & - & - & - \\
NG & 0.29 & 0.13 & 0.90 & 3.75 & -1.83 & 0.59 & 19.69 & 4.00 & 0.64 \\
OL & 0.61 & 0.43 & 0.82 & 3.59 & -2.43 & 0.57 & 45.38 & -14.43 & 0.46 \\
RB & 0.35 & 0.21 & 0.92 & 4.86 & -3.48 & 0.56 & 44.71 & -23.61 & 0.56 \\
SB & 0.46 & 0.38 & 0.88 & 1.69 & 0.39 & 0.78 & - & - & - \\
FA & 0.89 & 0.42 & 0.82 & 4.03 & 1.81 & 0.46 & 36.97 & 0.19 & 0.75 \\
\hline
\end{tabular}


Table A5. Model performance statistics per coastal buoy location for JJA 2017, M5.

\begin{tabular}{cccccccccc}
\hline Station & & $\mathbf{H}_{\mathbf{m} \mathbf{0}}$ & & \multicolumn{3}{c}{$\mathbf{T}_{\mathbf{p}}$} & \multicolumn{3}{c}{ Peak Direction } \\
\hline ID & RMSD & Bias & Willmott & RMSD & Bias & Willmott & RMSD & Bias & Willmott \\
\hline CP & 0.40 & 0.03 & 0.96 & 1.18 & -0.03 & 0.84 & 12.84 & -2.27 & 0.76 \\
DB & 0.44 & 0.23 & 0.79 & 2.68 & 0.13 & 0.71 & 30.90 & -7.90 & 0.79 \\
MB & 0.33 & 0.02 & 0.82 & 1.39 & -0.53 & 0.82 & - & - & - \\
NG & 0.27 & 0.05 & 0.85 & 1.61 & -0.38 & 0.78 & 15.20 & 6.13 & 0.51 \\
OL & 0.46 & 0.22 & 0.84 & 1.62 & -0.52 & 0.78 & 29.99 & -10.09 & 0.50 \\
RB & 0.33 & 0.09 & 0.88 & 2.43 & -0.38 & 0.75 & 31.41 & -13.68 & 0.66 \\
SB & 0.39 & 0.31 & 0.91 & 1.37 & 0.24 & 0.81 & - & - & - \\
FA & 0.74 & 0.21 & 0.81 & 3.65 & 1.98 & 0.41 & 32.99 & 0.44 & 0.66 \\
\hline
\end{tabular}

Table A6. Model performance statistics per coastal buoy location for JJA 2017, M6.

\begin{tabular}{cccccccccc}
\hline Station & & $\mathbf{H}_{\mathbf{m} 0}$ & & \multicolumn{3}{c}{$\mathbf{T}_{\mathbf{p}}$} & \multicolumn{3}{c}{ Peak Direction } \\
\hline ID & RMSD & Bias & Willmott & RMSD & Bias & Willmott & RMSD & Bias & Willmott \\
\hline CP & 0.52 & 0.29 & 0.93 & 1.37 & -0.08 & 0.80 & 17.04 & -2.11 & 0.72 \\
DB & 0.67 & 0.58 & 0.68 & 4.25 & -2.52 & 0.53 & 35.58 & -11.37 & 0.76 \\
MB & 0.40 & 0.21 & 0.78 & 1.81 & -0.62 & 0.74 & - & - & - \\
NG & 0.41 & 0.31 & 0.77 & 2.09 & -0.54 & 0.70 & 17.29 & 4.76 & 0.50 \\
OL & 0.67 & 0.53 & 0.75 & 2.31 & -1.06 & 0.69 & 43.33 & -16.97 & 0.35 \\
RB & 0.47 & 0.36 & 0.82 & 3.69 & -1.89 & 0.65 & 40.25 & -19.87 & 0.57 \\
SB & 0.43 & 0.35 & 0.88 & 1.46 & 0.32 & 0.79 & - & - & - \\
FA & 0.91 & 0.51 & 0.76 & 2.90 & 1.51 & 0.55 & 36.71 & -2.85 & 0.64 \\
\hline
\end{tabular}

\section{Appendix C (Statistical Correlations Used in the Present Study)}

Here, $p$ will be the predicted values and $r$ the reference values. $N$ is the total number of values being compared. In the following definitions an overbar denotes an average. The following statistical definitions thus follow:

$$
\begin{gathered}
\text { bias }=\frac{\sum_{n=1}^{N} p_{n}-r_{n}}{N}, \\
R M S D^{2}=\frac{\sum_{n=1}^{N}\left(p_{n}-r_{n}\right)^{2}}{N}, \\
c R M S D^{2}=\frac{\sum_{n=1}^{N}\left[\left(p_{n}-\overline{p_{n}}\right)-\left(r_{n}-\overline{r_{n}}\right)\right]^{2}}{N} \\
\text { and Willmott }=1-\left[\sum_{n=1}^{N} \frac{\left(p_{n}-r_{n}\right)^{2}}{\sum_{n=1}^{N}\left(\left|p_{n}^{\prime}\right|-\left|r_{n}^{\prime}\right|\right)^{2}}\right],
\end{gathered}
$$

where $p_{n}^{\prime}=p_{n}-\bar{r}$ and $r_{n}^{\prime}=r_{n}-\bar{r}$ and $\bar{r}$ is the average of all the reference data. A Willmott index equal to 1 , indicates a perfect match between predicted and reference. SI (the Scatter Index) is determined by dividing the RMSD by the mean of the observations and multiplying it by 100 .

\section{References}

1. McKinney, T.E.; Davidson, B. Facts about the African Past. Phylon (1960-) 1960, 21, 196. [CrossRef]

2. Crétat, J.; Richard, Y.; Pohl, B.; Rouault, M.; Reason, C.; Fauchereau, N. Recurrent daily rainfall patterns over South Africa and associated dynamics during the core of the austral summer. Int. J. Clim. 2010, 32, 261-273. [CrossRef]

3. Gramcianinov, C.B.; Hodges, K.I.; De Camargo, R. The properties and genesis environments of South Atlantic cyclones. Clim. Dyn. 2019, 53, 4115-4140. [CrossRef] 
4. Rautenbach, C.; Daniels, T.; De Vos, M.; Barnes, M.A. A coupled wave, tide and storm surge operational forecasting system for South Africa: Validation and physical description. Nat. Hazards 2020, 103, 1407-1439. [CrossRef]

5. Veitch, J.; Rautenbach, C.; Hermes, J.; Reason, C. The Cape Point wave record, extreme events and the role of large-scale modes of climate variability. J. Mar. Syst. 2019, 198, 103185. [CrossRef]

6. Amrutha, M.; Kumar, V.S.; Sandhya, K.; Nair, T.M.B.; Rathod, J. Wave hindcast studies using SWAN nested in WAVEWATCH III-comparison with measured nearshore buoy data off Karwar, eastern Arabian Sea. Ocean Eng. 2016, 119, 114-124. [CrossRef]

7. Zheng, C.; Li, C.Y. Analysis of temporal and spatial characteristics of waves in the Indian Ocean based on ERA-40 wave reanalysis. Appl. Ocean Res. 2017, 63, 217-228. [CrossRef]

8. Pérez, J.; Méndez, F.; Menéndez, M.; Losada, I.J. ESTELA: A method for evaluating the source and travel time of the wave energy reaching a local area. Ocean Dyn. 2014, 64, 1181-1191. [CrossRef]

9. Camus, P.; Menéndez, M.; Méndez, F.; Izaguirre, C.; Espejo, A.; Cánovas, V.; Pérez, J.; Rueda, A.; Losada, I.J.; Medina, R. A weather-type statistical downscaling framework for ocean wave climate. J. Geophys. Res. Oceans 2014, 119, 7389-7405. [CrossRef]

10. Semedo, A.; Suselj, K.; Rutgersson, A.; Sterl, A. A Global View on the Wind Sea and Swell Climate and Variability from ERA-40. J. Clim. 2011, 24, 1461-1479. [CrossRef]

11. Chen, G.; Chapron, B.; Ezraty, R.; VanDeMark, D. A Global View of Swell and Wind Sea Climate in the Ocean by Satellite Altimeter and Scatterometer. J. Atmos. Ocean. Technol. 2002, 19, 1849-1859. [CrossRef]

12. Camus, P.; Losada, I.J.; Izaguirre, C.; Espejo, A.; Menéndez, M.; Pérez, J. Statistical wave climate projections for coastal impact assessments. Earth's Future 2017, 5, 918-933. [CrossRef]

13. Morim, J.; Hemer, M.; Wang, X.L.; Cartwright, N.; Trenham, C.; Semedo, A.; Young, I.; Bricheno, L.; Camus, P.; Casas-Prat, M.; et al. Robustness and uncertainties in global multivariate wind-wave climate projections. Nat. Clim. Chang. 2019, 9, 711-718. [CrossRef]

14. Young, I.; Ribal, A. Multiplatform evaluation of global trends in wind speed and wave height. Science 2019, 364, 548-552. [CrossRef] [PubMed]

15. Marcos, M.; Rohmer, J.; Vousdoukas, M.I.; Mentaschi, L.; Le Cozannet, G.; Amores, A. Increased Extreme Coastal Water Levels Due to the Combined Action of Storm Surges and Wind Waves. Geophys. Res. Lett. 2019, 46, 4356-4364. [CrossRef]

16. Ardhuin, F.; Stopa, J.E.; Chapron, B.; Collard, F.; Husson, R.; Jensen, R.E.; Johannessen, J.; Mouche, A.; Passaro, M.; Quartly, G.; et al. Observing Sea States. Front. Mar. Sci. 2019, 6, 1-29. [CrossRef]

17. Anderson, R.; Bill, C.; Branch, G.; Brown, B.; Hara, M.; Harris, J. Waves of Change; University of Cape Town Press: Cape Town, South Africa, 2003.

18. Corbella, S.; Stretch, D.D. Multivariate return periods of sea storms for coastal erosion risk assessment. Nat. Hazards Earth Syst. Sci. 2012, 12, 2699-2708. [CrossRef]

19. Seabloom, E.W.; Ruggiero, P.; Hacker, S.D.; Mull, J.; Zarnetske, P.L. Invasive grasses, climate change, and exposure to storm-wave overtopping in coastal dune ecosystems. Glob. Chang. Boil. 2012, 19, 824-832. [CrossRef]

20. Melet, A.; Meyssignac, B.; Almar, R.; le Cozannet, G. Under-estimated wave contribution to coastal sea-level rise. Nat. Clim. Chang. 2018, 8, 234-239. [CrossRef]

21. Morris, T.; Rautenbach, C.; Stander, J. A new era for marine forecasting in South Africa. S. Afr. J. Sci. 2019, 115, 1-2. [CrossRef]

22. Quilfen, Y.; Yurovskaya, M.V.; Chapron, B.; Ardhuin, F. Storm waves focusing and steepening in the Agulhas current: Satellite observations and modeling. Remote Sens. Environ. 2018, 216, 561-571. [CrossRef]

23. Barnes, M.A.; Rautenbach, C. Toward Operational Wave-Current Interactions over the Agulhas Current System. J. Geophys. Res. Oceans 2020, 125, 1-21. [CrossRef]

24. De León, S.P.; Soares, C.G. Sensitivity of wave model predictions to wind fields in the Western Mediterranean sea. Coast. Eng. 2008, 55, 920-929. [CrossRef]

25. Gorrell, L.; Raubenheimer, B.; Elgar, S.; Guza, R. SWAN predictions of waves observed in shallow water onshore of complex bathymetry. Coast. Eng. 2011, 58, 510-516. [CrossRef]

26. Hoque, A.; Perrie, W.; Solomon, S.M. Application of SWAN model for storm generated wave simulation in the Canadian Beaufort Sea. J. Ocean Eng. Sci. 2020, 5, 19-34. [CrossRef] 
27. Rautenbach, C.; Barnes, M.A.; De Vos, M. Tidal characteristics of South Africa. Deep. Sea Res. Part I Oceanogr. Res. Pap. 2019, 150, 103079. [CrossRef]

28. Vaze, P.; Neeck, S.; Bannoura, W.; Green, J.; Wade, A.; Mignogno, M.; Zaouche, G.; Couderc, V.; Thouvenot, E.; Parisot, F. The Jason-3 Mission: Completing the transition of ocean altimetry from research to operations. In Proceedings of the Sensors, Systems, and Next-Generation Satellites XIV, Toulouse, France, 20-23 September 2010; Volume 7826, p. 78260Y.

29. Verron, J.; Sengenes, P.; Lambin, J.; Noubel, J.; Steunou, N.; Guillot, A.; Picot, N.; Coutin-Faye, S.; Sharma, R.; Gairola, R.M.; et al. The SARAL/AltiKa Altimetry Satellite Mission. Mar. Geodesy 2015, 38, 2-21. [CrossRef]

30. Cummings, J.A.; Smedstad, O.M. Variational Data Assimilation for the Global Ocean. In Data Assimilation for Atmospheric, Oceanic and Hydrologic Applications (Vol. II); Springer: Berlin/Heidelberg, Germany, 2013; pp. 303-343.

31. Harding, J.; Rigney, J. Operational Oceanography in the U.S. Navy: A GODAE Perspective. In Ocean Weather Forecasting; Springer: Berlin/Heidelberg, Germany, 2006; pp. 467-482.

32. Brown1, A.R.; Milton, S.; Cullen, M.; Golding, B.; Mitchell, J.; Shelly, A. Unified Modeling and Prediction of Weather and Climate: A 25-Year Journey. Bull. Am. Meteorol. Soc. 2012, 93, 1865-1877. [CrossRef]

33. Tolman, H.L. A Third-Generation Model for Wind Waves on Slowly Varying, Unsteady, and Inhomogeneous Depths and Currents. J. Phys. Oceanogr. 1991, 21, 782-797. [CrossRef]

34. Tolman, H.L.; Balasubramaniyan, B.; Burroughs, L.D.; Chalikov, D.V.; Chao, Y.Y.; Chen, H.S.; Gerald, V.M. Development and Implementation of Wind-Generated Ocean Surface Wave Modelsat NCEP. Weather Forecast. 2002, 17, 311-333. [CrossRef]

35. WAVEWATCH III Development Group. User Manual and System Documentation of WAVEWATCH III ${ }^{\circledR}$ version 5.16; NOAA/NWS/NCEP/MMAB, Technical Note 329: College Park, MD, USA, 2016.

36. Tolman, H.L. A mosaic approach to wind wave modeling. Ocean Model. 2008, 25, 35-47. [CrossRef]

37. Rogers, W.E.; Linzell, R.S. The IRI Grid System for Use with WAVEWATCH III ${ }^{\circledR}$; NRL Memorandum Report 7320-18; Naval Research Laboratory: Washington, DC, USA, 2018.

38. Wittmann, P.A.; Cummings, J.A. Assimilation of Altimeter Wave Measurements into Wavewatch III, In 8th International Workshop on Wave Hindcasting and Foreecasting and 2nd Coastal Hazards Symposium, 2004; pp. 14-19. Available online: https://www.semanticscholar.org/paper/Assimilation-of-AltimeterWave-Measurements-into-Wittmann-Cummings/5d28aa4f6df6f93aaf9eda8a03e1b4ef2cc121fc (accessed on 30 August 2020).

39. Deltares, D. Delft3D Flexible Mesh Suite. In Delft3D-FLOW, User Manual; Deltares: Delft, The Netherlands, 2018.

40. Sembiring, L.; Van Ormondt, M.; Van Dongeren, A.; Roelvink, D. A validation of an operational wave and surge prediction system for the Dutch coast. Nat. Hazards Earth Syst. Sci. 2015, 15, 1231-1242. [CrossRef]

41. Komen, G.J.; Hasselmann, K. On the Existence of a Fully Developed Wind-Sea Spectrum. J. Phys. Oceanogr. 1984, 14, 1271-1285. [CrossRef]

42. Van Der Westhuysen, A.J.; Zijlema, M.; Battjes, J.A. Nonlinear saturation-based whitecapping dissipation in SWAN for deep and shallow water. Coast. Eng. 2007, 54, 151-170. [CrossRef]

43. Mulligan, R.P.; Bowen, A.J.; Hay, A.E.; Van Der Westhuysen, A.J.; Battjes, J.A. Whitecapping and wave field evolution in a coastal bay. J. Geophys. Res. Space Phys. 2008, 113, 1-16. [CrossRef]

44. Madsen, O.S.; Poon, Y.-K.; Graber, H.C. Spectral Wave Attenuation by Bottom Friction: Theory. In Proceedings of the 21st International Conference on Coastal Engineering, Malaga, Spain, 20-25 June 1988; pp. 492-504.

45. Battjes, J.A.; Janssen, J.P. Energy Loss and Set-Up Due to Breaking of Random Waves. Coast. Eng. 1978 1978, 2, 569-587.

46. Holthuijsen, L.H. Waves in Oceanic and Coastal Waters; Cambridge University Press (CUP): Cambridge, UK, 2007.

47. Gweba, B. Developing a Methodology for the Assessment of Wave Energy along the South African Coast. Ph.D. Thesis, Stellenbosch University, Stellenbosch, South Africa, 2018.

48. Longuet-Higgins, M.S.; Cartwright, D.E.; Smith, N. Observations of the directional spectrum of sea waves using the motions of a floating buoy. Ocean Wave Spectra 1961, 111-132.

49. Oltman-Shay, J.; Guza, R.T. A Data-Adaptive Ocean Wave Directional-Spectrum Estimator for Pitch and Roll Type Measurements. J. Phys. Oceanogr. 1984, 14, 1800-1810. [CrossRef]

50. Lygre, A.; Krogstad, H.E. Maximum Entropy Estimation of the Directional Distribution in Ocean Wave Spectra. J. Phys. Oceanogr. 1986, 16, 2052-2060. [CrossRef] 
51. Earle, M.; Steele, K.; Wang, D. Use of advanced directional wave spectra analysis methods. Ocean Eng. 1999, 26, 1421-1434. [CrossRef]

52. Williams, J.J.; Esteves, L.S. Guidance on Setup, Calibration, and Validation of Hydrodynamic, Wave, and Sediment Models for Shelf Seas and Estuaries. Adv. Civ. Eng. 2017, 2017, 1-25. [CrossRef]

53. Cavaleri, L.; Abdalla, S.; Benetazzo, A.; Bertotti, L.; Bidlot, J.-R.; Øyvind, B.; Carniel, S.; Jensen, R.; Portilla-Yandún, J.; RogersiD, E.; et al. Wave modelling in coastal and inner seas. Prog. Oceanogr. 2018, 167, 164-233. [CrossRef]

54. Taylor, K.E. Summarizing multiple aspects of model performance in a single diagram. J. Geophys. Res. Space Phys. 2001, 106, 7183-7192. [CrossRef]

55. Maze, G. Taylor Diagram. 2010. Available online: http://codes.guillaumemaze.org/ (accessed on 5 July 2020).

56. Toffoli, A.; Bitner-Gregersen, E.M. Types of Ocean Surface Waves, Wave Classification. In Encyclopedia of Maritime and Offshore Engineering; John Wiley \& Sons, Ltd.: Chichester, UK, 2017; pp. 1-8.

57. Kolbusz, J.; Pattiaratchi, C.; Mann, L. Validation of the wave climate in south-west Australia predicted using the Climate Forecast System Reanalysis. Aust. J. Marit. Ocean Aff. 2015, 7, 3-11. [CrossRef]

58. Jolliff, J.; Kindle, J.C.; Shulman, I.; Penta, B.; Friedrichs, M.A.M.; Helber, R.; Arnone, R.A. Summary diagrams for coupled hydrodynamic-ecosystem model skill assessment. J. Mar. Syst. 2009, 76, 64-82. [CrossRef]

59. Van Der Westhuysen, A.; Van Dongeren, A.; Groeneweg, J.; Van Vledder, G.P.; Peters, H.; Gautier, C.; Van Nieuwkoop, J.C.C. Improvements in spectral wave modeling in tidal inlet seas. J. Geophys. Res. Space Phys. 2012, 117, C11. [CrossRef]

60. Van Der Westhuysen, A.J. Modeling of depth-induced wave breaking under finite depth wave growth conditions. J. Geophys. Res. Space Phys. 2010, 115, C01008. [CrossRef]

61. Collins, J.I. Prediction of shallow-water spectra. J. Geophys. Res. Space Phys. 1972, 77, 2693-2707. [CrossRef]

62. Rogers, D.E.; Babanin, A.; Wang, D.W. Observation-Consistent Input and Whitecapping Dissipation in a Model for Wind-Generated Surface Waves: Description and Simple Calculations. J. Atmos. Ocean. Technol. 2012, 29, 1329-1346. [CrossRef]

63. Willmott, C.J. On the validation of models. Phys. Geogr. 1987, 2, 184-194. [CrossRef]

64. Willmott, C.J.; Robeson, M.; Matsuura, K. Short Communication A refined index of model performance. Int. J. Climatol. 2012, 2094, 2088-2094. [CrossRef] 